\title{
Integrative analysis of the 3D genome structure reveals that CTCF maintains the properties of mouse female germline stem cells
}

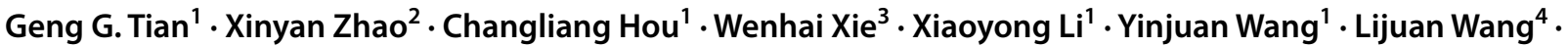 \\ Hua $\mathrm{Li}^{5} \cdot$ Xiaodong $\mathrm{Zhao}^{6} \cdot$ Jing $\mathrm{Li}^{7} \cdot \mathrm{Ji} \mathrm{Wu}^{1,2} \mathbb{0}$
}

Received: 23 November 2021 / Revised: 17 December 2021 / Accepted: 20 December 2021 / Published online: 3 January 2022

(c) The Author(s) 2022

\begin{abstract}
The three-dimensional configuration of the genome ensures cell type-specific gene expression profiles by placing genes and regulatory elements in close spatial proximity. Here, we used in situ high-throughput chromosome conformation (in situ Hi-C), RNA sequencing (RNA-seq) and chromatin immunoprecipitation sequencing (ChIP-seq) to characterize the highorder chromatin structure signature of female germline stem cells (FGSCs) and identify its regulating key factor based on the data-driven of multiple omics data. By comparison with pluripotent stem cells (PSCs), adult stem cells (ASCs), and somatic cells at three major levels of chromatin architecture, A/B compartments, topologically associating domains, and chromatin loops, the chromatin architecture of FGSCs was most similar to that of other ASCs and largely different from that of PSCs and somatic cells. After integrative analysis of the three-dimensional chromatin structure, active compartment-associating loops (aCALs) were identified as a signature of high-order chromatin organization in FGSCs, which revealed that CCCTCbinding factor was a major factor to maintain the properties of FGSCs through regulation of aCALs. We found FGSCs belong to ASCs at chromatin structure level and characterized aCALs as the high-order chromatin structure signature of FGSCs. Furthermore, CTCF was identified to play a key role in regulating aCALS to maintain the biological functions of FGSCs. These data provide a valuable resource for future studies of the features of chromatin organization in mammalian stem cells and further understanding of the fundamental characteristics of FGSCs.
\end{abstract}

Keywords Stem cell $\cdot$ Chromatin structure $\cdot \mathrm{Hi}-\mathrm{C} \cdot \mathrm{CTCF}$

Geng G. Tian, Xinyan Zhao and Changliang Hou contributed equally.

$\mathrm{Ji} \mathrm{Wu}$

jiwu@sjtu.edu.cn

Xiaodong Zhao

xiaodongzhao@sjtu.edu.cn

Jing Li

jing.li@sjtu.edu.cn

1 Renji Hospital, Key Laboratory for the Genetics of Developmental and Neuropsychiatric Disorders (Ministry of Education), Bio-X Institutes, School of Medicine, Shanghai Jiao Tong University, Shanghai 200240, China

2 Key Laboratory of Fertility Preservation and Maintenance of Ministry of Education, Ningxia Medical University, Yinchuan 750004, China

3 Westlake Laboratory of Life Sciences and Biomedicine, School of Life Sciences, Westlake University, Hangzhou 310024, Zhejiang, China
4 Key Laboratory of Bioorganic Synthesis of Zhejiang Province, College of Biotechnology and Bioengineering, Zhejiang University of Technology, Hangzhou 310014, China

5 State Key Laboratory for Oncogenes and Bio-ID Center, School of Biomedical Engineering, Shanghai Jiao Tong University, 800 Dongchuan Road, Shanghai 200240, China

6 Shanghai Center for Systems Biomedicine, Shanghai Jiao Tong University, Shanghai 200240, China

7 Department of Bioinformatics and Biostatistics, School of Life Sciences and Biotechnology, Shanghai Jiao Tong University, 800 Dongchuan Road, Shanghai 200240, China 


\section{Introduction}

The chromatin architecture of germline stem cells (GSCs) carries the information necessary for cells to perform their unique functions and is thus an essential factor in the transmission of the genome from generation to generation. GSCs renew themselves and differentiate into gametes that include sperm and metaphase II (MII) oocytes [1-3]. During this process, spermatogonial stem cells (SSCs) differentiate into sperm by packaging chromatin into a highly condensed configuration. Recently identified female GSCs (FGSCs) in postnatal ovaries differentiate into MII oocytes after transplantation into the ovaries of infertile mice [2-8]; thereby, reshaping the concept that female mammals lose their ability to produce oocytes at birth [9, 10]. Unlike other stem cells, GSCs undergo meiosis to produce haploid gametes with chromatin remodeling. It is therefore necessary to characterize the chromatin structure of GSCs during their development to further understand GSC biology.

High-throughput chromosome conformation (Hi-C) is a powerful technology to study genome-wide architecture, which allows the high-order chromatin structure to be displayed and reveals the chromatin organization in the nucleus [11]. The spatial organization of chromatin as the structural and functional basis of the genome affects DNA localization with important roles in regulation of gene expression to ensure DNA duplication and other biological processes $[12,13]$, which suggests a close connection to the biological functions and signature of the cell. Dixon et al. found extensive chromatin reorganization during specification of human embryonic stem (ES) cell-derived lineages by mapping genome-wide chromatin interactions in human ES cells and four human ES cellderived lineages [14]. Previous studies have reported that the chromatin architecture changes dynamically during spermatogenesis with dissolved and reappeared topologically associating domains (TADs) and A/B compartments $[15,16]$. The high-order chromatin organization exhibits statistically significant differences between sperm and embryonic fibroblasts $[17,18]$. However, the signature of the chromatin architecture of FGSCs is unknown.

CCCTC-binding factor (CTCF) is a critical regulator of chromatin architecture, which underlies its functions that include gene expression and three-dimensional (3D) genome construction and regulation [19-22]. In mammals, CTCF recognizes chromatin insulators to segment chromatin into several TADs. Therefore, disruption of CTCF expression can led to the disappearance of TAD formation [23]. Notably, CTCF regulates gene expression through the formation of chromatin loops [19, 20]. A recent study has reported that CTCF plays an important role in establishment of the 3D chromatin structure during human embryogenesis, which indicates that CTCF is also important for development [24]. However, the 3D architectural role of CTCF in FGSCs is unknown.

In this study, we used in situ Hi-C technology to compare the chromatin organizations of FGSCs and induced pluripotent stem cells (iPSCs), adult stem cells (ASCs), which included SSCs and neural stem cells (NSCs), and somatic cells (mouse SIM embryonic fibroblasts; STO cells) to explore the chromosome structure characteristics of FGSCs. Together with RNA sequencing (RNA-seq) and chromatin immunoprecipitation sequencing (ChIP-seq), we identified distinct features (active compartment-associating loops; aCALs) of the chromatin organization in FGSCs at three major levels: A/B compartments, TADs, and chromatin loops, and found that FGSCs were most similar to other ASCs and largely different from iPSCs and STO cells. By further analysis of the distinct features, we revealed that CTCF may be a crucial factor to maintain the properties of FGSCs through regulation of the high-order chromatin structure.

\section{Materials and methods}

\section{Animals}

The CAG-EGFP mice from the Model Animal Research Center of Nanjing University, also named C57BL/6-Tg (CAG-EGFP) C14-Y01-FM131-Osb [25]. The Ddx4-Cre; $\mathrm{mT} / \mathrm{mG}$ mice were generated as described previously [26]. DBA/2 mice were obtained from the Shanghai Slac Laboratory Animal Co., Ltd. (Shanghai, China). All procedures involving animals were approved by the Institutional Animal Care and Use Committee (IACUC) at Shanghai Jiao Tong University, and all experiments were performed in accordance with the approved protocols.

\section{Isolation and culture of SSCS}

Mouse SSCs were isolated and cultured from 6-day-old male $\mathrm{F}_{1}$ progeny of DBA $/ 2 \times$ CAG-EGFP mice, as previously described [27]. In brief, SSCs ( $>20$ passages) were cultured on mitomycin C (MMC)-treated mouse embryonic fibroblast (MEF) feeder cells with SSC culture medium. The SSC culture medium included StemPro-34 SFM supplemented with StemPro supplement (Invitrogen, Carlsbad, CA, USA), human basic fibroblast growth factor $(100 \mu \mathrm{g} / \mathrm{ml}$ transferrin, $25 \mu \mathrm{g} / \mathrm{ml}$ insulin, $10 \mathrm{ng} / \mathrm{ml}$; Invitrogen), recombinant human epidermal growth factor $(20 \mathrm{ng} / \mathrm{ml}$; Invitrogen), recombinant human glial cell line-derived neurotrophic factor $(10 \mathrm{ng} / \mathrm{ml}$; Invitrogen), D-(+)-glucose (6 mg/ml; Invitrogen), putrescine (60 mM; Invitrogen), sodium selenite (30 nM; Invitrogen), 
L-glutamine ( $2 \mathrm{mM}$; Invitrogen), pyruvic acid $(30 \mu \mathrm{g}$ / $\mathrm{ml})$, DL-lactic acid $(1 \mu \mathrm{l} / \mathrm{ml}$; Sigma, St. Louis, MO, USA), bovine serum albumin ( $5 \mathrm{mg} / \mathrm{ml}$; Sigma), 2-mercaptoethanol (10 $\mu \mathrm{M}$; Sigma), 1× MEM vitamin solution (Invitrogen), $1 \times$ nonessential amino acid solution (Invitrogen), ascorbic acid $(0.1 \mathrm{mM})$, D-biotin $(10 \mu \mathrm{g} / \mathrm{ml}$; Sigma $), 1 \%$ fetal bovine serum (Gibco), and $1 \times$ penicillin/streptomycin solution (Invitrogen). The medium was changed every $2-3$ days.

\section{Isolation and culture of FGSCs}

Mouse FGSCs were isolated and cultured from neonatal Ddx4-Cre; $\mathrm{mT} / \mathrm{mG}$ mouse ovaries (6 days old), as previously described [26]. Briefly, FGSCs ( $>18$ passages) were cultured on mitotically inactivated STO (SIM mouse embryoderived thioguanine- and ouabain-resistant) cell feeders in minimum essential medium alpha (MEM $\alpha$; Invitrogen) supplemented with $10 \%$ fetal bovine serum (FBS) (Life Technologies), mouse leukemia inhibitory factor (10 ng/ $\mathrm{ml}$; Santa Cruz Biotechnology), mouse epidermal growth factor (EGF) (20 ng/ml; PeproTech), basic fibroblast growth factor (bFGF) (10 ng/ml; PeproTech), mouse glial cell linederived neurotrophic factor (GDNF) $(10 \mathrm{ng} / \mathrm{ml}$; PeproTech), nonessential amino acids (1 $\mathrm{mM}$; Life Technologies), L-glutamine ( $2 \mathrm{mM}$; Sigma), pyruvate ( $30 \mathrm{mg} / \mathrm{ml}$; Amresco), and $\beta$-mercaptoethanol ( $50 \mathrm{mM}$; Biotech). The FGSCs were subcultured every 4-7 days.

\section{Isolation and culture of NSCs}

NSCs were isolated from E12.5 mouse embryonic cortex, in accordance with a previously described procedure [28, 29]. The primary NSCs were seeded onto poly-L-ornithine (Sigma-Aldrich)- and laminin (Invitrogen)-coated dishes, cultured as monocultures. Neural basal medium with EGF (20 ng/ml; PeproTech), bFGF (20 ng/ml; PeproTech), heparin $(20 \mathrm{ng} / \mathrm{ml}$; Sigma-Aldrich), and 2\% B27 (Invitrogen) was used as NSC proliferation medium. For differentiation, NSCs were seeded on poly-L-ornithine (Sigma-Aldrich)and laminin (Invitrogen)-coated dishes. Upon NSC attachment, the medium was changed to differentiation medium identical to the NSC proliferation medium without growth factors (EGF and bFGF). After differentiation for 10 days, neural- and glial-specific markers were used to determine the differentiation potential of cultured NSCs.

\section{STO culture}

STOs were maintained in Dulbecco's modified Eagle's medium (DMEM) with high glucose (Life Technologies), 10\% FBS (Life Technologies), 1\% nonessential amino acids (Life Technologies), glutamine (2 mM; Sigma), and penicillin $(100 \mathrm{U} / \mathrm{ml}$; Sigma)/streptomycin $(0.1 \mathrm{mg} / \mathrm{ml}$; Sigma) at $37{ }^{\circ} \mathrm{C}$ and $5 \% \mathrm{CO}_{2}$, and passaged after $3-4$ days.

\section{Knockdown of CTCF in FGSCs}

To examine the function of CTCF in mouse FGSCs, the following shRNAs targeting CTCF were designed and synthesized by OBiO Technology (Shanghai, China) Corp., Ltd (Suppl. Table S5). Then, the sequence with the best interference effect was used for lentivirus packaging. The sequences of shRNA were CTCF: 5'-GCGAAAGCAGCATTCCTA T- $3^{\prime}$. For lentivirus infection, $60-70 \%$ cell on 48 -well plate incubated with 1:1 mixture of culture medium and lentivirus solution. After overnight infection, we changed fresh culture medium and cultured for $12 \mathrm{~h}$. To select for positive cells, $100 \mathrm{ng} / \mathrm{ml}$ puromycin was added to the FGSC culture medium for $72 \mathrm{~h}$. The surviving FGSCs cells were collected and analyzed by qRT-PCR.

\section{Immunofluorescence}

The immunofluorescence procedure was performed as described previously with minor modification [30]. Cultured cells were washed twice with phosphate-buffered saline (PBS) and then fixed in 4\% paraformaldehyde for $15 \mathrm{~min}$. After that the cells were rinsed twice and incubated with PBS containing $0.1 \%$ (v/v) Triton X-100 for $15 \mathrm{~min}$. Fixed cells were blocked by $10 \%$ normal horse serum in PBS for $10 \mathrm{~min}$ at room temperature. The cells were then incubated with primary antibodies: mouse monoclonal antiNESTIN and rabbit polyclonal anti-SOX2 (1:180 dilution; Abcam), mouse polyclonal anti-TUJ-1 and rabbit polyclonal anti-GFAP (1:150 dilution; Abcam), mouse monoclonal anti-MVH (1:500 dilution; Abcam), mouse monoclonal anti-PLZF (1:100 dilution; Santa Cruz Biotechnology). After $1 \mathrm{~h}$ of incubation at room temperature with the primary antibodies, the cells were rinsed twice in PBS and then incubated in the dark with a fluorescein isothiocyanateconjugated secondary antibody, either goat antirabbit IgG or goat anti-mouse IgG (1:200 dilution; Proteintech, Chicago, IL, USA) for $60 \mathrm{~min}$ at $37^{\circ} \mathrm{C}$. This was followed by rinsing and staining of the nucleus with 4',6-diamidino-2-phenylindole (DAPI) (1:1000 dilution; Sigma)-containing PBS for $10 \mathrm{~min}$ at room temperature. After washing twice with PBS, the cells were examined in fresh PBS under an inverted fluorescence microscope (Leica).

\section{Western blot assay}

Protein extracts were separated by $7-12 \%$ SDS-polyacrylamide gel electrophoresis (PAGE), and then transferred to $0.45 \mu \mathrm{m}$ PVDF membranes. The membrane was blocked in 5\% TBST milk for $1 \mathrm{~h}$ and probed overnight with antibodies 
against CTCF (1:3000, Sigma-Aldrich). The membrane was thrice washed in $0.1 \%$ TBS-Tween-20, incubated with diluted secondary antibodies (Proteintech) in 5\% PBST milk for $2 \mathrm{~h}$ and the antigen-antibody reaction was visualized by enhanced chemiluminescence assay (ECL, Thermo). Western blot quantification was performed with ImageJ software.

\section{Cell proliferation assay}

Cell proliferation rates was assayed using the cell counting kit-8 (Genomeditech, Shanghai, China) and Cell-Light EdU Apollo ${ }^{\circledR} 567$ in Vitro Imaging Kit (RiboBio, Guangzhou, China) according to the manufacturer's instructions. In brief, for CCK8 assay, $10 \mu \mathrm{l} \mathrm{CCK8}$ solution was added to each well containing $100 \mu \mathrm{l}$ medium. The plate was incubated for additional $4 \mathrm{~h}$ before measuring the absorbance at $450 \mathrm{~nm}$ wavelength. For EdU labeling assay, the 5-ethynyl2 -deoxyuridine (EdU) was added to each well for $2 \mathrm{~h}$, and the cells were fixed and stained by $1 \times$ Apollo for $30 \mathrm{~min}$. Then, the cell nucleus was counterstained with $1 \times$ Hoechst 33342. The stained cells were examined with Leica fluorescence microscope and photographed with camera.

\section{RT-PCR and qRT-PCR}

Total RNA from cells was extracted using Trizol reagent (Invitrogen), in accordance with the manufacturer's instructions. After extraction, total RNA ( $1 \mu \mathrm{g})$ was used to synthesize cDNA with Primescript Reverse Transcriptase (ThermoFisher). qRT-PCR analysis was carried out with SYBR Premix Ex Taq (YEASEN, Shanghai, China) in a 20ul volume on an Applied Biosystems 7500 Real-Time PCR System. Specific marker genes, such as Mvh, Oct4, Fragilis, Stella, Dazl, Exv5, Plzf, Gfral, Nestin, Sox2, Pax6, Olig2, Ascll, Gfap, Meikin, Prdm9, Hspalb, Majin, and Notch2, were used to characterize the cells. Gapdh was used as an internal control. Primer sequences are listed in Supplementary Table S1.

\section{In situ Hi-C library generation}

Cells were used for in situ Hi-C, including iPSCs (from Kang's Lab, Tongji University), FGSCs (collection with fluorescence activated cell sorting, FACS), SSCs, NSCs, and STOs [31]. $\mathrm{Hi}-\mathrm{C}$ libraries were generated in accordance with the standard in situ Hi-C protocol, with minor modification [19]. Five million cells were harvested with $0.05 \%$ trypsin, washed twice, resuspended with DMEM medium and then crosslinked with 37\% formaldehyde (F8775; Sigma) to a final concentration of $1 \%$ for $10 \mathrm{~min}$ at room temperature. Formaldehyde was quenched by adding glycine to a final concentration of $0.2 \mathrm{M}$ and the cells were incubated for $5 \mathrm{~min}$ at room temperature, then transferred to ice for $20 \mathrm{~min}$. The fixed cells were centrifuged at $400 \times g$ and $4{ }^{\circ} \mathrm{C}$ and washed with cold PBS once, followed by storage at $-80{ }^{\circ} \mathrm{C}$. Fixed cells were resuspended in lysis buffer and then incubated on ice for $30 \mathrm{~min}$. Nuclei were pelleted by centrifugation at $3000 \times g$ for $5 \mathrm{~min}$ and washed once with $500 \mu \mathrm{l}$ of cold lysis buffer. The pellet was resuspended in $0.5 \%$ sodium dodecyl sulfate (SDS) and incubated at $62{ }^{\circ} \mathrm{C}$ for 5-10 min. Then, SDS was quenched by adding water $(145 \mu \mathrm{l})$ and $10 \%$ Triton X-100 (25 $\mu \mathrm{l})$ and incubated at $37^{\circ} \mathrm{C}$ for $15 \mathrm{~min}$. The nuclei were digested overnight at $37{ }^{\circ} \mathrm{C}$ with $100 \mathrm{U}$ Mbol restriction enzyme $(20 \mu \mathrm{l}$; NEB, R0417) and 10× NEBuffer $2(25 \mu \mathrm{l})$. The next day, the nuclei were incubated at $62{ }^{\circ} \mathrm{C}$ for $20 \mathrm{~min}$, followed by cooling to room temperature. A mixed solution $(50 \mu \mathrm{l})(37.5 \mu \mathrm{l}$ of $0.4 \mathrm{mM}$ biotin-14-dATP, $1.5 \mu \mathrm{l}$ of $10 \mathrm{mM}$ dCTP, $1.5 \mu \mathrm{l}$ of $10 \mathrm{mM}$ dGTP, $1.5 \mu \mathrm{l}$ of $10 \mathrm{mM}$ dTTP, and $8 \mu \mathrm{l}$ of $5 \mathrm{U} / \mu \mathrm{l}$ DNA Polymerase I) was then added and incubated at $37{ }^{\circ} \mathrm{C}$ for $2 \mathrm{~h}$. Ligation master mix ( $663 \mu \mathrm{l}$ of water, $120 \mu \mathrm{l}$ of $10 \mathrm{x}$ NEB T4 DNA ligase buffer, $100 \mu \mathrm{l}$ of $10 \%$ Triton X-100, $12 \mu \mathrm{l}$ of $10 \mathrm{mg} / \mathrm{ml}$ bovine serum albumin, and $5 \mu \mathrm{l}$ of $400 \mathrm{U} / \mu \mathrm{l} \mathrm{T} 4$ DNA ligase) was added to a volume of $900 \mu \mathrm{l}$ and slowly rotated for $6 \mathrm{~h}$ at room temperature. Next, to degrade protein, proteinase $\mathrm{K}(50 \mu \mathrm{l}$ of final concentration $20 \mathrm{mg} / \mathrm{ml})$ and $10 \%$ SDS $(120 \mu \mathrm{l})$ were added and incubated at $55{ }^{\circ} \mathrm{C}$ for $30 \mathrm{~min}$. Then, sodium chloride $(5 \mathrm{M}, 130 \mu \mathrm{l})$ was added and incubated at $68{ }^{\circ} \mathrm{C}$ overnight. On the third day, the DNA was purified by adding $1.6 \times$ volumes of pure ethanol and $0.1 \times$ volumes of sodium acetate $(3 \mathrm{M}), \mathrm{pH}$ 5.2. Subsequently, DNA was diluted with Tris buffer and sheared by a Digital Sonifier (Branson). Dynabeads MyOne Streptavidin T1 beads ( $50 \mu \mathrm{l}$; Thermo Scientific) were added and washed once with $1 \times$ Tween washing buffer (TWB) (5 mM Tris-HCl (pH 7.5), 0.5 mM EDTA, $1 \mathrm{M} \mathrm{NaCl}, 0.05$ Tween 20), separated on a magnet, and then the solution was discarded. The beads were resuspended in $2 \times$ binding buffer (10 mM Tris- $\mathrm{HCl}(\mathrm{pH}$ 7.5), $1 \mathrm{mM}$ EDTA, $2 \mathrm{M} \mathrm{NaCl}$ ), mixed with the DNA, and incubated at room temperature for $1 \mathrm{~h}$ with rotation, followed by washing twice with TWB $(500 \mu \mathrm{l})$ and reclaiming the beads using a magnet. The beads were next resuspended with a mixture [ $88 \mu \mathrm{l}$ of $1 \times \mathrm{NEB}$ T4 DNA ligase buffer with $10 \mathrm{mM}$ ATP, $2 \mu \mathrm{l}$ of $25 \mathrm{mM}$ dNTP mix, $5 \mu \mathrm{l}$ of $10 \mathrm{U} / \mu \mathrm{l}$ NEB T4 PNK, $4 \mu \mathrm{l}$ of $3 \mathrm{U} / \mu \mathrm{l}$ NEB T4 DNA polymerase I, $1 \mu \mathrm{l}$ of $5 \mathrm{U} / \mu \mathrm{l}$ NEB DNA polymerase I, Large (Klenow) Fragment] and incubated at room temperature for $30 \mathrm{~min}$, followed by separation on a magnet and washing twice with $1 \times$ TWB. The beads were resuspended with mixture $(90 \mu \mathrm{l}$ of $1 \times$ NEBuffer $2,5 \mu \mathrm{l}$ of $10 \mathrm{mM}$ dATP, $5 \mu \mathrm{l}$ of $5 \mathrm{U} / \mu \mathrm{l}$ NEB KlenowExo Minus) and incubated at $37{ }^{\circ} \mathrm{C}$ for $30 \mathrm{~min}$. Then, separation on a magnet was performed, after which the solution was discarded and washing was carried out twice. The beads were resuspended in $1 \times$ NEB Quick ligation reaction buffer $(50 \mu \mathrm{l}$; NEB), and NEB DNA Quick ligase $(2 \mu \mathrm{l} ; \mathrm{NEB})$ and an Illumina indexed adapter of NEBNext Multiplex Oligos for Illumina ( $3 \mu \mathrm{l}$; NEB) were added at room temperature for $15 \mathrm{~min}$. Then, USER enzyme of NEBNext 
Multiplex Oligos for Illumina ( $3 \mu \mathrm{l})$ was added to the ligation mixture at $37{ }^{\circ} \mathrm{C}$ for $15 \mathrm{~min}$. The DNA was washed twice and eluted by resuspending the beads with Tris- $\mathrm{HCl}(50 \mu \mathrm{l}$ of $10 \mathrm{mM}$; pH 8.0), followed by incubation at $98^{\circ} \mathrm{C}$ for $10 \mathrm{~min}$. The DNA suspension was transferred into a fresh tube and stored at $-20{ }^{\circ} \mathrm{C}$. The Hi-C library was amplified in a PCR system $(25 \mu$ l of NEBNext Q5 Hot Start HiFi PCR mix, $5 \mu 1$ of index primer of NEBNext Multiplex Oligos for Illumina, $5 \mu \mathrm{l}$ of universal primer of NEBNext Multiplex Oligos for Illumina, and $15 \mu \mathrm{l}$ of DNA template) with the following PCR conditions: initial denaturation at $98^{\circ} \mathrm{C}$ for $30 \mathrm{~s}$; eight cycles of denaturation at $98{ }^{\circ} \mathrm{C}$ for $10 \mathrm{~s}$ and annealing/extension at $65^{\circ} \mathrm{C}$ for $75 \mathrm{~s}$; followed by final extension at $65^{\circ} \mathrm{C}$ for $5 \mathrm{~min}$, and then maintenance at $4{ }^{\circ} \mathrm{C}$. The DNA fraction in the size range of 300-500 bp was selected using Agencourt AMPure XP beads (Beckman Coulter). The DNA was eluted with $1 \times$ Tris- $\mathrm{HCl}$ buffer $(33 \mu \mathrm{l})$ and incubated at room temperature for $5 \mathrm{~min}$, followed by separation on a magnet and transfer of the solution to a fresh labeled tube. This produced the final $\mathrm{Hi}-\mathrm{C}$ library. The quality of the Hi-C library was determined using the Qubit dsDNA HS Assay and Agilent 2100 DNA 1000 HS kit. The high-quality libraries were sequenced using an Illumina sequencing platform.

\section{ChIP-Seq library preparation}

The preparation of ChIP and input DNA libraries was performed as previously described [32]. In brief, two cells were crosslinked with $1 \%$ formaldehyde for $5 \mathrm{~min}$ at room temperature and quenched with glycine $(125 \mathrm{mM})$. Cells were then put on ice, resuspended in cold cell lysis buffer [140 mM $\mathrm{NaCl}, 1$ mM EDTA pH 8.0, 1\% Triton X-100, 0.1\% SDS, and protease inhibitors (Roche)]. Nuclei were sonicated into fragments of 200-1000 bp in size. The chromatin fragments were precleared and then immunoprecipitated with Protein A + G magnetic beads coupled with anti-H3K4me3 (ab8580; Abcam), anti-H3K27ac (ab4729; Abcam), anti-H3K27me3 (07-449; Millipore), and anti-CTCF (ab70303; Abcam). After reverse crosslinking, immunoprecipitated DNA and input DNA were end-repaired and adapters were ligated to the DNA fragments using NEBNext Ultra End-Repair/dATailing Module (E7442; NEB) and NEBNext Ultra Ligation Module (E7445; NEB). High-throughput sequencing of the ChIP fragments was performed using Illumina NextSeq 500, following the manufacturer's protocol.

\section{Hi-C data processing, mapping, and ICE normalization}

$\mathrm{Hi}-\mathrm{C}$ pair-end was trimmed of adaptor sequences and lowquality reads were filtered with BBmap (version 38.16). HiCPro (version 2.7) [33] was then used to map, process, and perform iterative correction for normalization. Reads were independently aligned to the mouse reference genome (mm9) with the bowtie2 algorithm [34]. Uncut DNA reads, re-ligation reads, continuous reads, and PCR artifacts were discarded. We then constructed a contact matrix using the unique mapped reads (MAPQ $>10$ ). We divided the genome into sequential bins of equal size and valid read pairs were then binned at a specific resolution. ICE [35] normalization was applied to remove bias in the raw matrix, such as GC content, mappability, and effective fragment length in $\mathrm{Hi}-\mathrm{C}$ data. Contact matrices were finally generated at binning resolutions of 10, 20, 40, 200, and $400 \mathrm{~kb}$.

\section{Validation of Hi-C data}

The data reproducibility was confirmed by calculating Pearson's correlation coefficient between the two Hi-C repeats. For each possible interaction $I_{i j}$ between two replicates, these were correlated by comparing each point's interaction in the normalized interaction matrix. Considering that the interaction matrix was highly skewed toward proximal interactions, we calculated the correlation to a maximum distance restricted to $2 \mathrm{Mb}$ between points $i$ and $j$. R was used to calculate Pearson's correlation between two duplicates.

\section{Contact probability $p(s)$ calculation}

$p(s)$ only considering intra interactions, was calculated with normalized interaction matrices at $40-\mathrm{kb}$ resolution, as described previously [36]. Briefly, we divided the genome into $40-\mathrm{kb}$ bins and counted the number of interactions at corresponding distances for each distance (separated by 40 , $80,120,160 \mathrm{~kb}$, etc.). We then divided the number of interactions in each bin by the total number of possible region reads as $p(s)$. Finally, we normalized the sum of $p(s)$ over the range of distances as 1 . The curve (log-log axis) was generated by locally weighted scatterplot smoothing.

\section{Identification of A and B compartments}

The R package (HiTC) [37] was used to generate the PC1 eigenvectors using 400-kb normalized matrices with pca. hic function, using the options: (normPerExpected=TRUE, $n p c=1$ ), for which a positive value indicates the A compartment and a negative value indicated the B compartment. To investigate compartment switching, we defined switched bins only if the PC1 eigenvectors changed in the same direction for two replicates.

\section{Identification of concordant genes with A/B compartment switch}

We defined genes with concordant changes in expression and compartment status according to a previously described 
method, with minor modifications [14]. Briefly, the covariance between the vector of the gene expression values (FPKM) and the vector of PC1 values for each gene was calculated across five cell types. We then used the covariance metric to quantitatively define 'concordance'. The observed covariance values were compared with a random background distribution to calculate a $p$ value for the covariance for each gene. Randomly shuffling the vector of FPKM for each gene produced the background distribution, and then obtained the covariance between the PC1 values and the random gene expression vector. A rank-based $p$ value could be calculated for the observed covariance values with 1000 repeats for each gene. Concordant genes were defined as those with a $p$ value $<0.01$.

\section{TAD calling and TAD boundaries}

We calculated the location of the TADs using the directional index (DI) value, as previously described [38]. We first calculated the DI value for each bin based on the ICEnormalized and depth-normalized matrix and then used this value as the input for a hidden Markov model (HMM) to call TADs. TAD boundaries were defined as those $<400 \mathrm{~kb}$.

\section{TAD signal calculation}

We calculated TADs signals using the insulation score [39]. The insulation score for each bin in the $20 \mathrm{~kb}$ was calculated by the average number of interactions that occurred across each bin. Using this matrix, we then plotted the insulation score distribution centered in the FGSC TADs (up/down to 0.5 TAD).

\section{Identification of chromatin loops and calculation of APA score}

We carried out chromatin loop calling using the tool (Juicer), as described previously [19]. The merged loops at different resolution as the calling chromatin loops. The calculation of APA score was followed the parameters: $-r$ 25,000, 1000.

\section{ChIP-Seq data analysis}

We aligned fastq files to the $\mathrm{mm} 9$ reference genome, removed PCR duplicates using Samtools (version 2.0.1) [40], and generated normalized genome coverage tracks from uniquely mapping reads (MAPQ > 10) using deepTools2 (version 3.1) [41]. Biological replicates were pooled, and coverage was then calculated as the average reads per million mapped reads (RPM) in 1-kb bins. To identify the correlation between ChIP-Seq and A/B compartment, we summed the $\log 2$ of the fold enrichment (treatment/input) from ChIP-Seq to calculate the relative ChIP-Seq signal in each compartment.

\section{RNA-Seq library generation and data analysis}

Total RNA was extracted from 2 to 6 million cells using Trizol Reagent (Invitrogen). The RNA quality was assessed using Agilent Bioanalyzer 2100. RNA-Seq libraries were prepared using the KAPA Stranded mRNA-Seq kit, following the manufacturer's instructions. After preparation, libraries were quantified using a Qubit fluorometer and sequenced with HiSeq Platform $(2 \times 150 \mathrm{bp})$. All RNA-Seq data were trimmed and aligned to the $\mathrm{mm} 9$ reference genome using Hisat2 (version 4.8.2) [42] with the default parameters. Gene expression FPKM was calculated by Cufflinks (version 2.2.1) [43] using the RefSeq database from the UCSC genome browser. Sequencing depth was normalized.

\section{GO term enrichment analysis}

GO term enrichment analysis was performed using the DAVID tool (version 6.8) [44], with a focus on enriched biological processes (BP). The GO results were displayed by Cytoscape (version 3.5.1) [45]. For the Benjamin-corrected $p$ value, a threshold of less than 0.05 was used for significance.

\section{Results}

\section{Biological characterization of FGSCs and other ASCs}

FGSCs were isolated from the ovaries of Ddx4-Cre;mT/ $\mathrm{mG}$ neonatal mice and cultured as described previously [26]. After culture for at least 18 passages, the cells exhibited a characteristic morphology similar to that previously described for FGSCs $[2,26]$. The expression of female germline marker genes was determined by reverse transcription-polymerase chain reaction (RT-PCR). FGSCs after long-term culture expressed Oct4, Fragilis, Mvh (mouse vasa homologue expressed exclusively in germ cells), Stella, Gfrol, and Dazl genes. Furthermore, immunofluorescence analysis revealed that these cells expressed MVH, which confirmed their identity as FGSCs (Fig. 1a).

We isolated SSCs from the testes of 6-day-old DBA/2x CAG-EGFP $F_{1}$ mice and cultured them as described previously [27]. Long-term cultured SSCs (>20 passages) were assessed by RT-PCR and found to express male germline marker genes [Etv5, Oct4, Plzf (promyelocytic leukemia zinc finger), Gfr $\alpha 1$, and $M v h$ ]. These results were confirmed by immunofluorescence and most cultured cells were also positive for PLZF expression, which confirmed their identity as SSCs (Fig. 1b). 
a

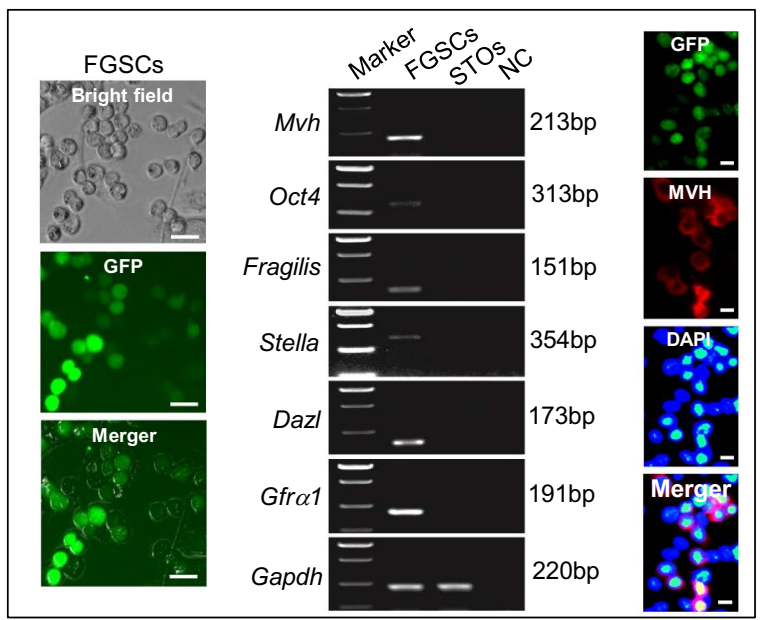

c
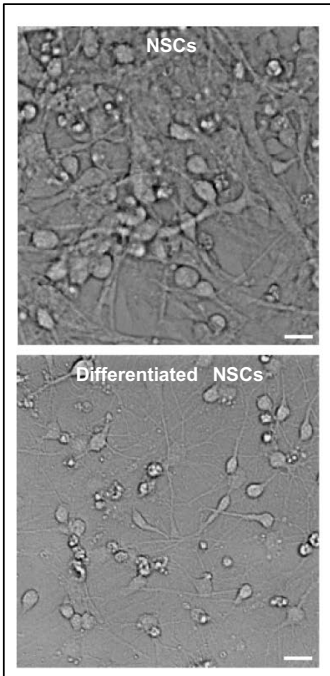

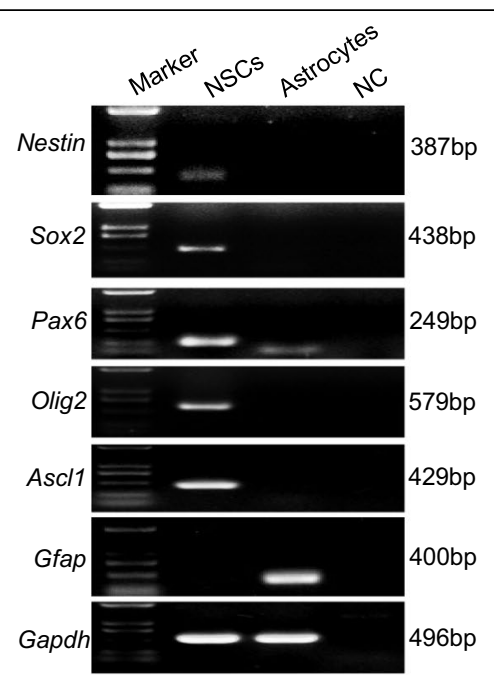

b
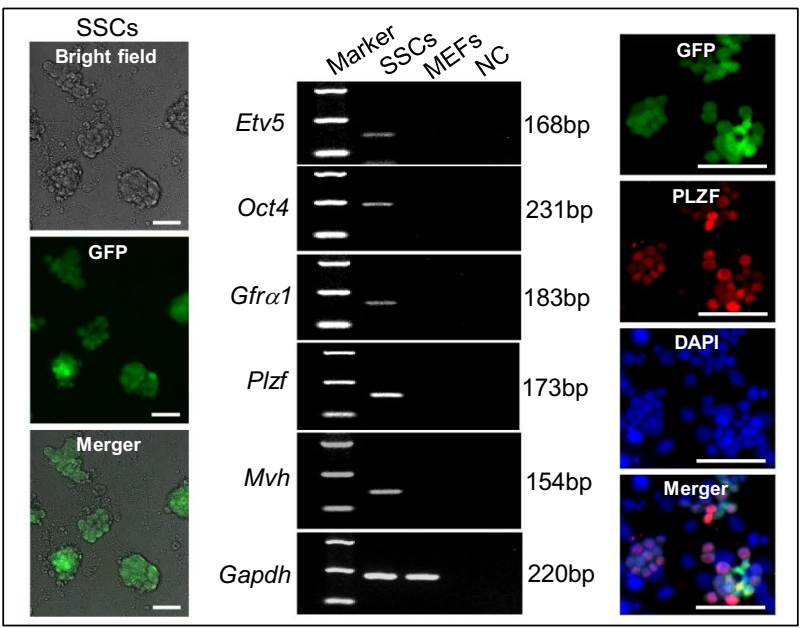

NSCs Differentiated NSCs Astrocytes

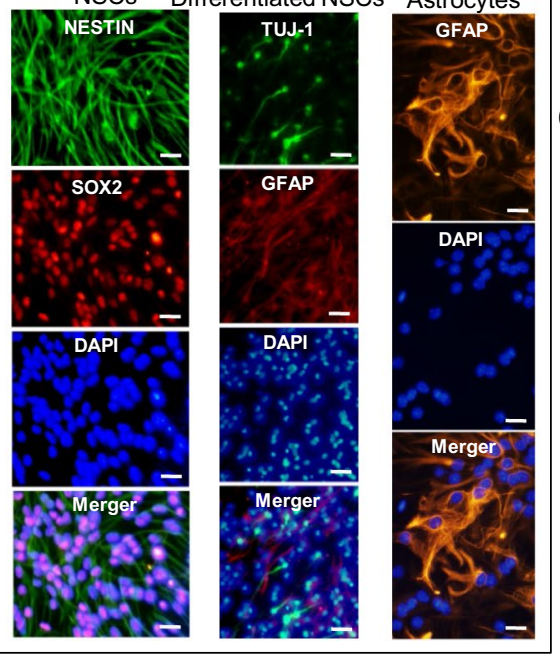

d

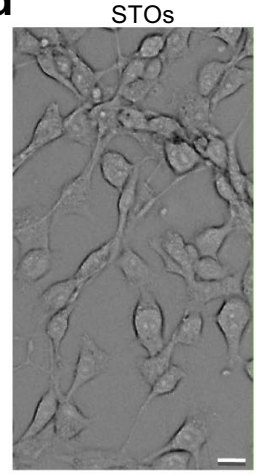

Fig. 1 Morphology and biological characteristics of FGSCs and other ASCs. a Morphology and biological characteristics of cultured FGSCs (>18 passages) from Ddx4-Cre; $\mathrm{mT} / \mathrm{mG}$ mice. Marker 100bp DNA marker. $N C$ negative control with water. Scale bar, $25 \mu \mathrm{m}$ (left) and $10 \mu \mathrm{m}$ (right). b Morphology and biological characteristics of cultured SSCs (>20 passages) from CAG-EGFP mice. Marker 100-bp DNA marker. $N C$ is negative control with water. Scale bar, $25 \mu \mathrm{m}$ (left) and $50 \mu \mathrm{m}$ (right). c Morphology and biological characteristics of cultured NSCs and astrocytes. Marker100-bp DNA marker. $N C$ is negative control with water. Scale bar, $10 \mu \mathrm{m}$. d Representative morphology of cultured STO cells. Scale bar, $10 \mu \mathrm{m}$

differentiation potential of cultured NSCs was confirmed by immunochemical staining of neural- and astrocyte-specific markers TUJ-1 ( $\beta 3$ tubulin) and GFAP (glial fibrillary acidic protein), respectively. These results confirmed the identity of the cultured cells as NSCs (Fig. 1c). The morphology of STO cells is shown in Fig. 1d.

\section{Global chromosome organization map of FGSCs}

To reveal the signature of the chromatin architecture in FGSCs, we performed in situ Hi-C [19] with two biological replicates of FGSCs and other cells (SSCs, NSCs, iPSCs, and STO cells), which generated approximately 400 million reads for each replicate. After filtering artificial reads and normalization, we obtained 2 billion valid $\mathrm{Hi}-\mathrm{C}$ reads over 
the five cell lines, which included an average of 207 million long range intrachromosomal cis-contacts and 90 million interchromosomal trans-contacts (Suppl. Table S1). We confirmed high reproducibility of the $\mathrm{Hi}-\mathrm{C}$ data (Suppl. Figure $\mathrm{S} 1$ ) and combined the two biological replicates into a single set of merged Hi-C data per cell type to reach a maximum resolution of $20 \mathrm{~kb}$.

An overview of the intrachromosomal contact heat maps revealed that FGSCs had a distinct chromatin organization (Fig. 2a). We further examined the characteristics of the chromatin organization by analyzing the patterns of the compartment status and TADs in autosomes across cells, which avoided sex chromosome effects. The compartment status was classified as active (A) or inactive (B) (Suppl. Table S2). The result showed FGSCs had different
A/B compartments compared with other cell types and the patterns of TADs or directional indexes (DIs) were almost the same for these cells (Fig. 2b). We counted the numbers of compartments and TADs in the cells and found that FGSCs had the lowest number of TADs and the number of compartments was similar to that in SSCs (Fig. 2c, Suppl. Table S3). We also calculated the average intrachromosomal contact probability of cells and found that the chromatin interaction frequency was decreased monotonically from $1 \times 10^{5}$ to $1 \times 10^{8} \mathrm{bp}$ for FGSCs and the other cells (Fig. 2d). The contact probability curves were similar in the five cell types from $1 \times 10^{5}$ to $1 \times 10^{8} \mathrm{bp}$, but changes were observed at the long-distance genome as reported previously [47].

a
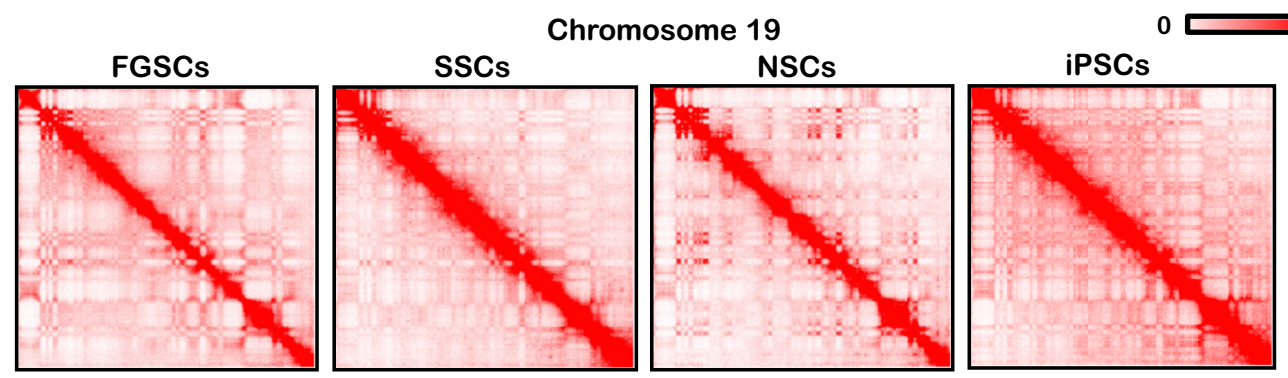

210

b
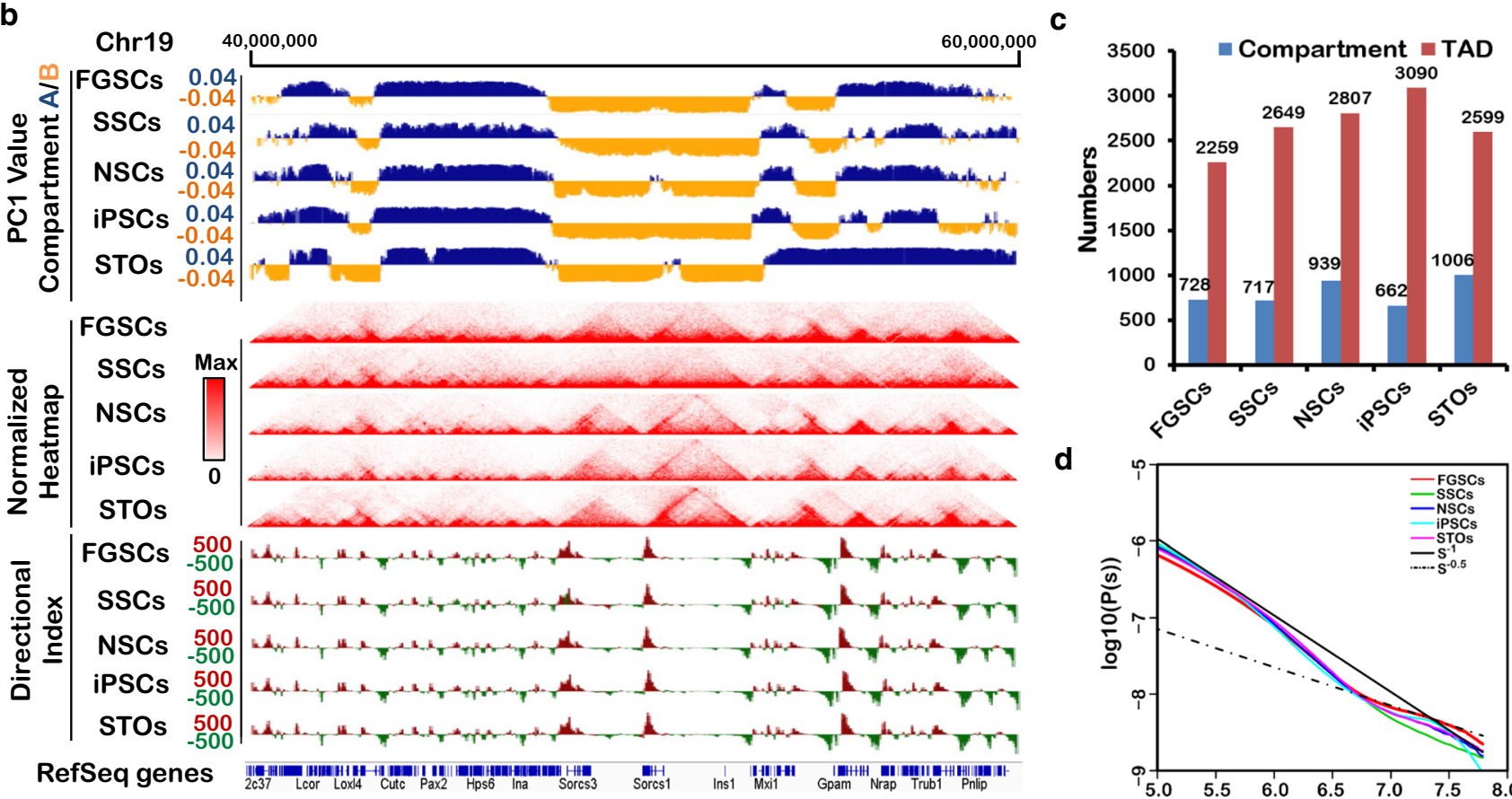

d

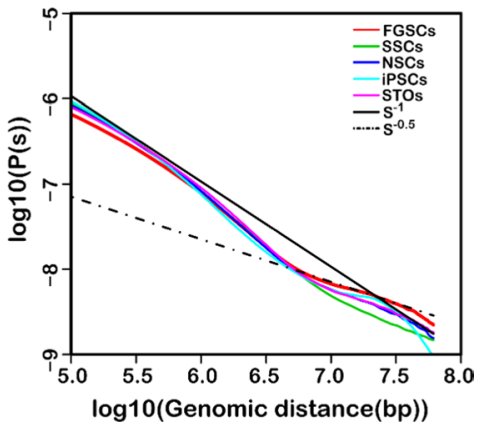

Fig. 2 Overall chromosome structure in FGSCs. a Contact matrices of chromosome 19 in FGSCs, SSCs, NSCs, iPSCs, and STO cells. b First principal component (PC1) value, normalized Hi-C interaction heat maps, and directional indexes (DIs) of FGSCs and other cells at the $20-\mathrm{kb}$ resolution. The $\mathrm{PC} 1$ value was used to indicate the A/B compartment status, where a positive $\mathrm{PC} 1$ value represented the A compartment (blue) and a negative value represented the B compartment (yellow). c Numbers of identified A/B compartments and TADs in FGSCs and other cells. d Average contact probability across the genome decreased as a function of the genomic distance 


\section{Compartment status distinguishes FGSCs from iPSCs}

Further systematic analysis of the compartment status across five cell types showed that FGSCs were more similar to NSCs and SSCs in terms of A/B compartments compared with iPSCs and STOs cells (Fig. 3a), suggesting that FGSCs were ASCs. Meanwhile, switching compartments of FGSCs accounted for about $40 \%$ proportion of compartments compared with iPSCs and STO cells, but a smaller proportion (30\%) compared with SSCs and NSCs (Suppl. Figure S2A). These results suggested that FGSCs had a unique A/B compartment status that was more similar to other ASCs than iPSCs or STO cells. Furthermore, RNA-seq data showed genes were highly expressed in compartment $\mathrm{A}$ than in compartment B (Suppl. Figure S2B). The genes located in the switching compartment tended to be differentially expressed compared with the stable compartments (Fig. 3b), which indicated that the compartment status was correlated with gene expression. Unexpectedly, go enrichment of the genes located in A compartment of FGSCs showed there was no female or stem cells related pathways (Suppl. Figure S2C). Then we asked whether there was a pattern of compartment status could reflect FGSCs' property. We used $K$-means method to cluster the PC1 value of compartment status of all cell types examined for characterizing FGSCs' property. The result showed compartment status could be divided two cluster: FGSC activation compartments and FGSC repression compartments (Fig. 3c), indicating the compartment A and B only present in FGSCs. Gene Ontology (GO) analysis of the genes with changed compartment status in FGSCs showed that it was particularly associated with stem cell population maintenance and cell proliferation (Fig. 3d), suggesting that FGSC activation compartments were highly related with FGSCs' biological property. a

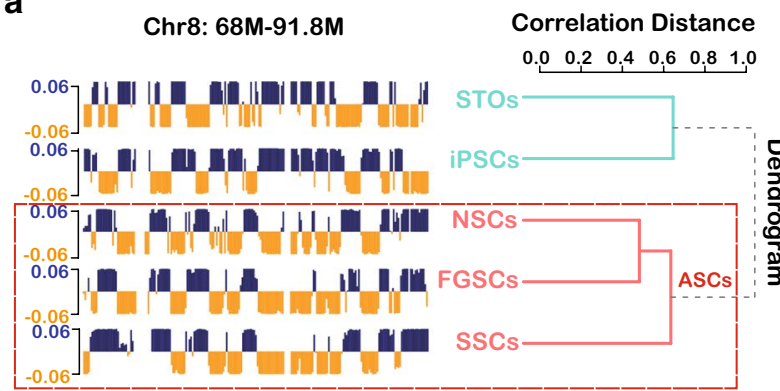

d

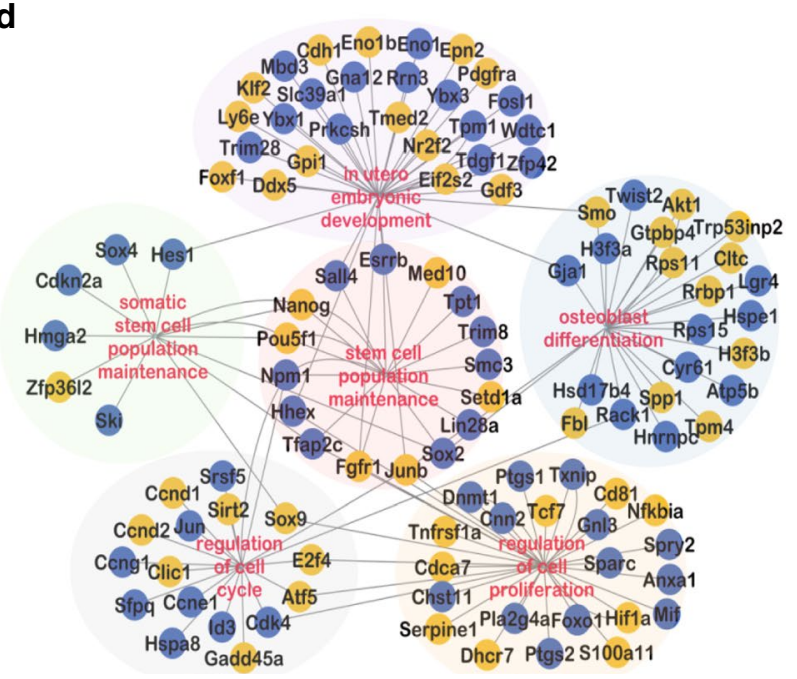

Fig. 3 FGSCs exhibit a specific compartment status. a FGSCs were similar to other ASCs (left: example of PC1 score represented compartment status across five types of cells; right: hierarchical clustering of PC1 score). b Genes that changed compartment status (A to $\mathrm{B}$ or B to A) or those that remained the same (stable) compared with FGSCs ( $p$ value by Wilcoxon's test). c $K$-means clustering $(k=2)$ of PC1 values of the genome that changed A/B compartment status

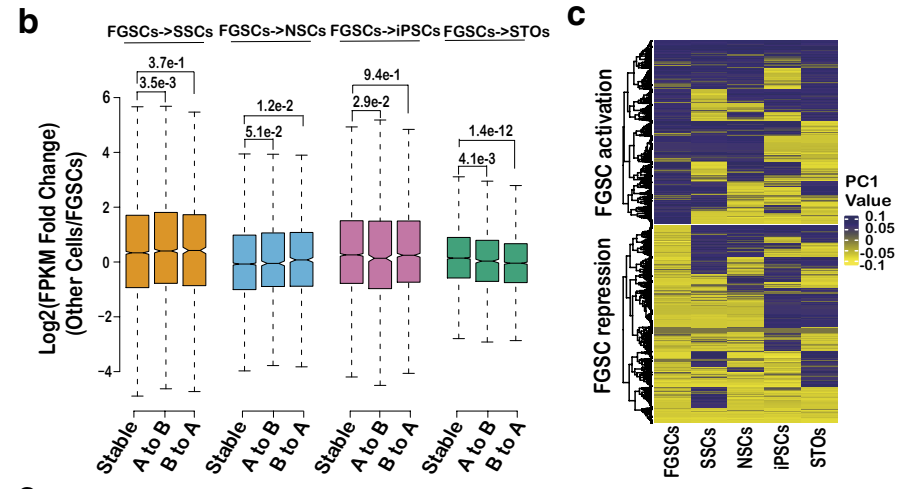

e

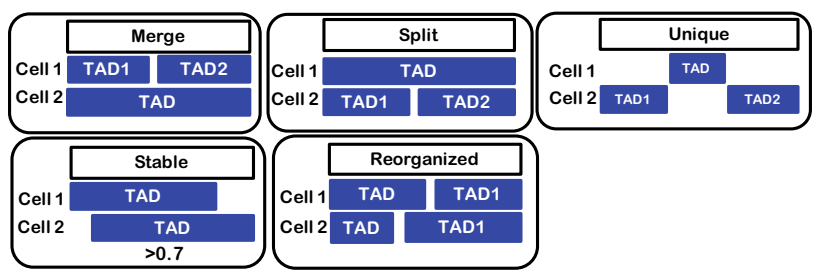

f

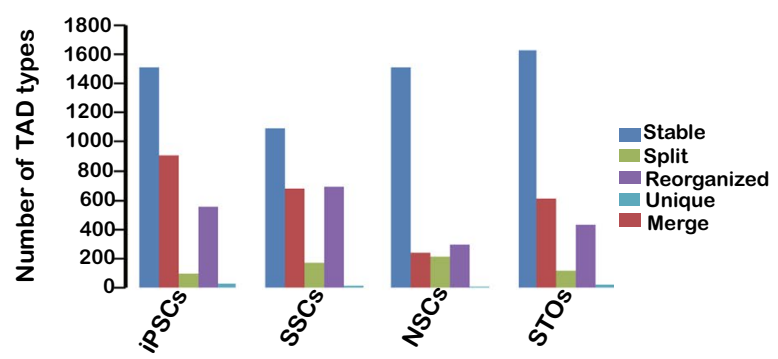

in FGSCs. d Display of the GO enrichment of genes with changed compartment status in FGSCs. Genes were circled in blue color represented that they were located in A compartment, while orange color represented that they were located in B compartment. Each biological process was colored in the background. $\mathbf{f}$ Comparison of gene expression between TADs and TAD boundaries 
We next identified TADs in FGSCs using the direction index (DI) (Suppl. Table S3). Well-defined TADs were occupied in $\sim 90 \%$ of the genome across cell types (Suppl. Figure S2D). According to the proportion of overlapping TADs compared with FGSCs, we classified the TADs into five types: stable, merged, split, reorganized, and unique (Fig. 3e). In which, two or more TADs in a stage fused into one TAD was defined as "merge"; one TAD divided into two or more TADs was defined as 'split'; and a TAD was unique in cells was defined as 'unique'. In addition to the merge, split, and unique TADs, a proportion of overlapping TADs $>0.70$ was defined this as 'stable', and other TADs were defined as 'reorganized'. We found most TADs were the stable type (Fig. 3f), which suggested that the TAD structure was highly stable across all five types of cells in accordance with a previous report [38]. Taken together, our data indicated that the compartment status was more characteristic than TADs and represented the features of cells across the five cell types.

\section{Active compartment-associating loops (aCALs) reveal the FGSC signature}

To systematically identify FGSC-specific functional chromatin loops using Juicer [19], we first identified 3332, 1064, 6031, 2941, and 5280 chromatin loops in FGSCs, SSCs, NSCs, iPSCs and STO cells, respectively (Suppl. Figure S3A,B). Next, we found that 3874, 1383, 5924, 3091, and 5031 genes in FGSCs, SSCs, NSCs, iPSCs and STO cells, respectively, were located in chromatin loops. Using a Venn diagram, we observed that 392 genes were shared across all cell types (cell type-shared loops) (Suppl. Figure S3C), which suggested that chromatin loops varied greatly among each cell type. To identify FGSC-specific chromatin loops, we further analyzed the data above. The results demonstrated that genes, which had formed chromatin loops located in compartments, had higher expression than in compartment boundaries and the compartment genes without chromatin loops forming in FGSCs (Fig. 4a). This suggested that the chromatin state-mediated compartment may contribute to gene regulation of chromatin loops. Further analysis of the expression of genes formed chromatin loops located in compartments showed they had highest expression in FGSCs compared with other type of cells (Fig. 4b), suggesting those specific loops were related with FGSCs. These specific loops were termed as compartmentassociating loops (CALs). We found that expression of genes and the PC1 score in CALs were higher than those out of CALs in FGSCs (Fig. 4c, d). In addition, the CALs were not related to the chromatin length, gene density, or TAD density (Suppl. Figure S4). Subsequently, by measuring the number of genes located in CALs per $1 \mathrm{Mbp}$, we observed that the distribution of gene number of CALs was not correlated with PC1 (Fig. 4e), which was not biased to A or
B compartment status. Interestingly, most of CALs (about 96\%) were located in TADs, but the expression of genes in CALs were higher than in TADs (Suppl. Figure S5A). When we divided the CALs into active (aCALs) and repressed CALs in accordance with the previously identified FGSC activation and repression compartment statuses, we found 1818 and 1262 genes located in aCALs and repressed CALs, respectively (Suppl. Figure S5B). By comparison with other cell types, we found aCALs were mostly specific to FGSCs (Suppl. Figure S5C). The genes located in aCALs were highly expressed in FGSCs compared with other cell types (Suppl. Figure S5D). GO analysis showed that the genes in aCALs were highly involved in female sex differentiation, female gonad development, and stem cell population maintenance, while genes in repressed CALs were related to male sex determination, embryonic organ development, and tissue morphogenesis (Fig. 4f). Those results indicated that the aCALs could be potentially the signature of FGSCs.

\section{CTCF is a potentially important factor in regulating aCALs of FGSCs}

To further investigate the factor involved in regulation of the chromatin architecture in FGSCs, we performed motif analysis of aCALs. As a result, the top motifs within aCAL regions matched the CTCF motifs (Fig. 5a), which suggested that CTCF may be an important factor involved in regulation of aCALs in FGSCs. Next, we performed ChIP-seq of CTCF in FGSCs and found that $\sim 86 \%$ of aCALs significantly overlapped with CTCF-binding sites (Suppl. Figure S6A, Fisher's test $p<2.2 \mathrm{e}-16$ ), which also suggested that CTCF plays a major role in the regulation of aCALs. Moreover, we observed that CTCF was enriched in the A compartment in FGSCs (Fig. 5b), which was in line with aCALs. By comparing the number of CTCF peaks between A and B compartments in FGSCs and iPSCs ${ }^{48}$, we found that CTCF was specifically enriched in the A compartment of FGSCs and not in iPSCs (Fig. 5c, Suppl. Figure S6B), which suggested specific enrichment of CTCF in the A compartment was FGSC and not in iPSCs. Furthermore, we found that genes located in aCALs had higher enrichment of CTCF than those out of aCALs (Fig. 5d). H3K4me3 and H3K27ac were also more enriched in the promoters of genes located in aCALs than in those out of aCALs (Suppl. Figure S6C), which suggested activation of more genes in aCALs. Subsequently, we identified 1566 overlapped genes between the CTCF-binding region and aCALs termed as CTCF-related aCAL genes. Indeed, RNA-seq results showed that CTCF-related aCAL genes had the highest expression among genes in and out of aCALs (Fig. 5e). Moreover, those CTCF-related aCALs genes had highest expression in FGSCs compared with other cell types, confirmed that those genes were related with FGSCs (Fig. 5f). GO analysis showed that the genes were 
a

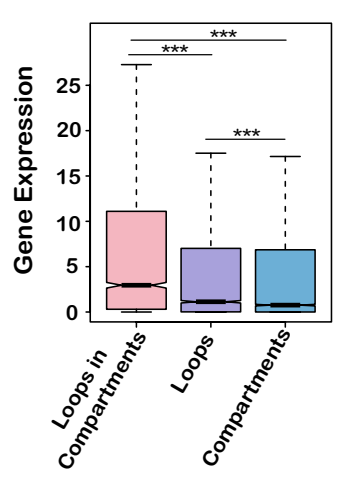

b

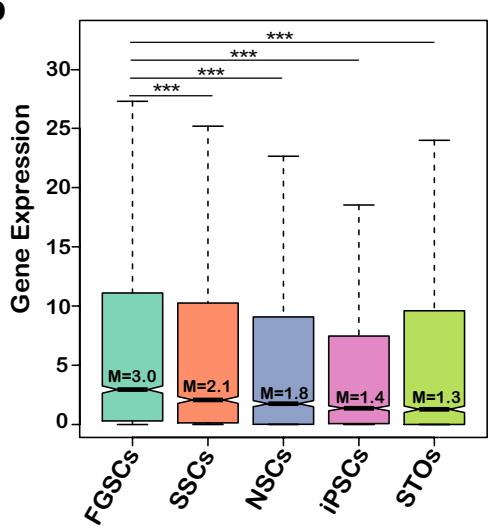

C

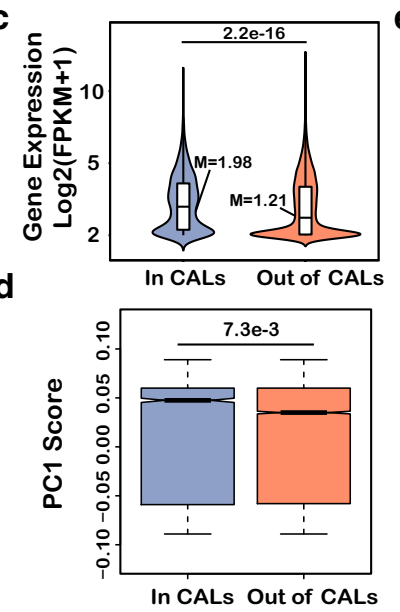

e

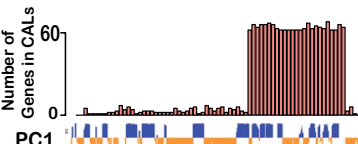

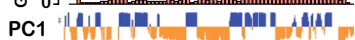

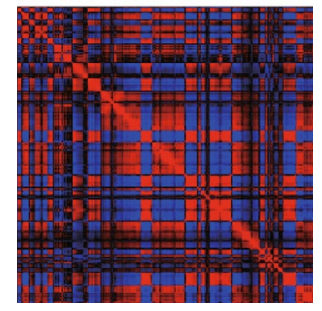

Chr12

f

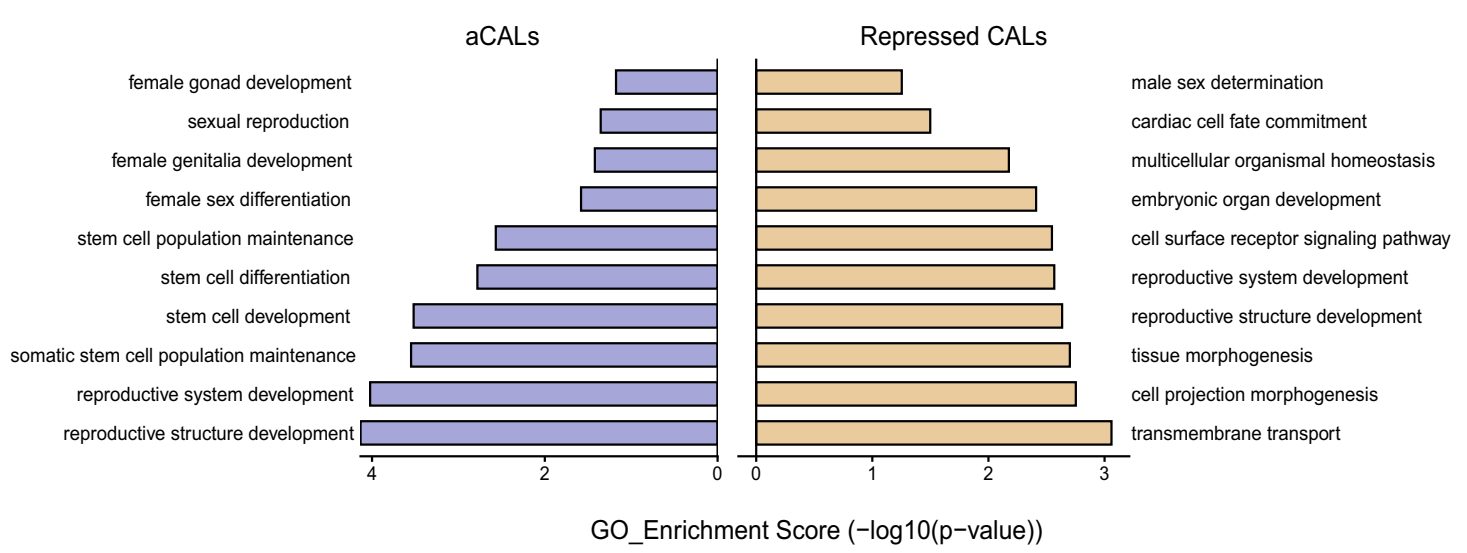

Fig. 4 aCALs reveal the FGSC signature. a Expression of genes located in chromatin loops and compartments, only in chromatin loops, and only in compartments in FGSCs ( $p$ value by Wilcoxon's test, $* * *$ represented $p<0.001)$. b Expression of genes located in chromatin loops and compartments across five type of cells ( $M$ means median; $p$ value by Wilcoxon's test, $* * *$ represented $p<0.001)$.

involved in stem cell population maintenance, reproductive structure development and female gonad development (Fig. 5g). Taken together, our data indicated that CTCF was a potentially important factor in regulating aCALs of FGSCs and possibly involved in FGSC development.

\section{CTCF maintains the biological functions of FGSCs}

To determine whether CTCF was implicated in the biological functions of FGSCs, we performed CTCF knockdown assays in FGSCs using short hairpin RNA (shRNA) technology (Suppl. Figure S7A). After CTCF knockdown in FGSCs, we observed that the size of FGSCs was obviously larger and the proliferative capacity of FGSCs was reduced significantly compared with the control (Fig. 6a-c). Furthermore, EdU incorporation assays demonstrated that the proportion of EdU-positive cells was significantly decreased in c Gene expression in CALs and out of CALs in FGSCs ( $M$ means median; $p$ value by Wilcoxon's test). d PC1 values in CALs and out of CALs in FGSCs ( $p$ value by Wilcoxon's test). e Example of chromosome 12 showed the Pearson's correlation heat map, $\mathrm{PC} 1$ value, and gene density of CALs in FGSCs. f GO enrichment of genes in aCALs or repressed CALs

the shCTCF group compared with the control (Fig. 6d). To clarify the reason why cells viability had declined and the size of FGSCs was larger after shCTCF treatment, we measured the expression of meiotic kinetochore factor (Meikin) and PR domain zinc finger protein 9 (Prdm9), which are differentiation related-genes of germline stem cells, by qRTPCR. Significant differences were found between the control and CTCF knockdown group (Fig. 6e). CTCF knockdown inhibited FGSC proliferation and induced FGSC differentiation. Next, RNA-seq data were generated from the CTCF knockdown group, which identified 2255 upregulated genes and 3321 downregulated genes (Fig. 6f). Notably, downregulated genes were enriched for stem cell population maintenance and mitotic sister chromatid segregation, while upregulated genes were related to stem cell differentiation and female gonad development (Fig. 6g). The expression of heat shock protein family A member 1B (Hspalb), membrane 
a

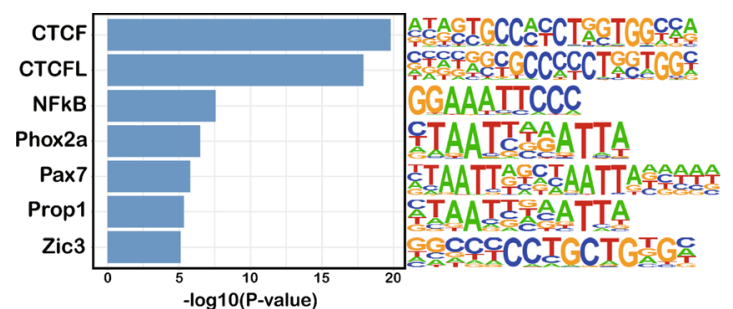

C

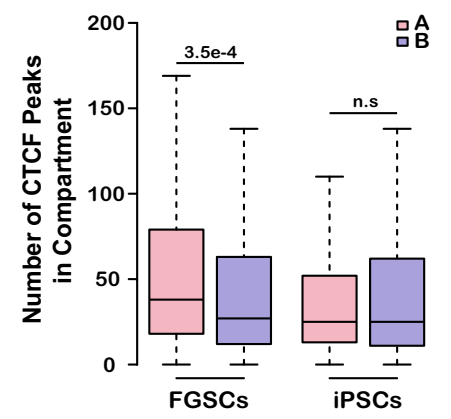

f

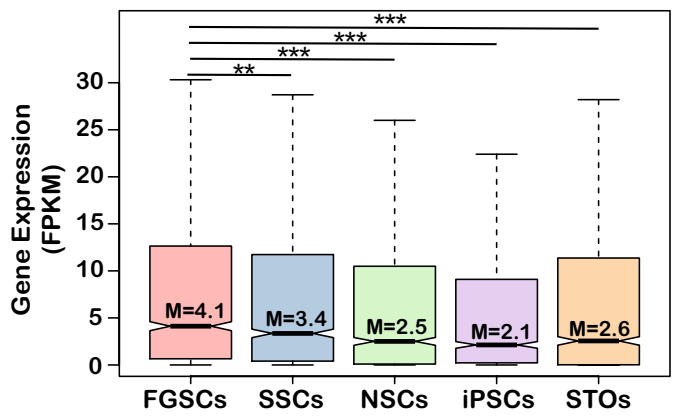

Fig. $5 \mathrm{CTCF}$ is a potential dominant factor in maintaining aCALs of FGSCs. a Motifs enriched in aCALs of FGSCs. b Snapshot of CTCF signals in A/B compartments in FGSCs. $\mathbf{c}$ Numbers of CTCF peaks in A/B compartments in FGSCs and iPSCs ( $p$ value by Wilcoxon's test). d Enrichment of CTCF signals in the gene promoter of aCALs and out of aCALs. e Expression of genes shared by CTCF

anchored junction protein (Majin), and Notch receptor 2 (Notch2), which are differentiation or proliferation relatedgenes of germline stem cells, was measured by qRT-PCR to validate the RNA-seq data (Suppl. Figure S7B). Among them, 486 genes of CTCF-related aCALs showed significantly different expression between CTCF knockdown and control groups, in which 224 genes were up-regulated and 262 genes were down-regulated in CTCF knockdown group (Suppl. Figure S7C). GO analyses showed that they were related to stem cell development and female gonad development (Suppl. Figure S7D), which is consistent with our previous findings that CTCF-related aCAL genes may have a dominant role in FGSC development. In summary, these results indicated that CTCF might maintain the biological functions of FGSCs through regulation of chromatin organization.

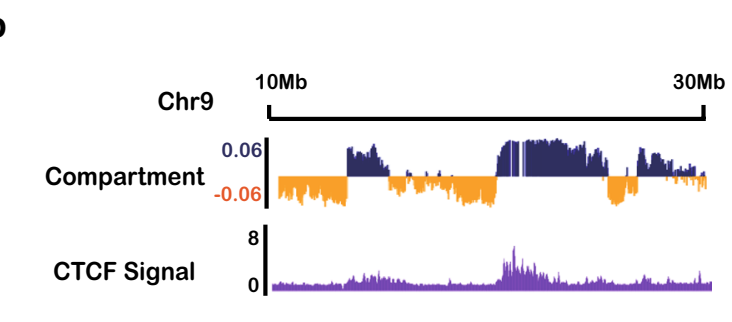

e

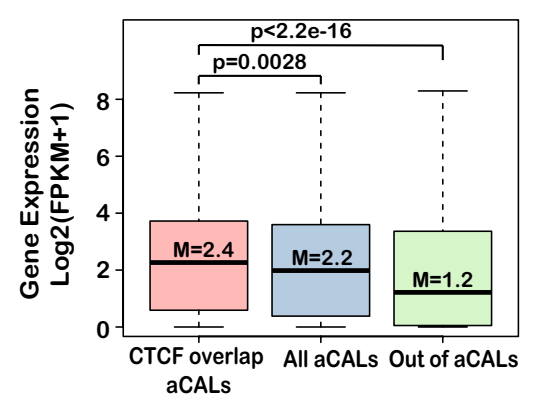

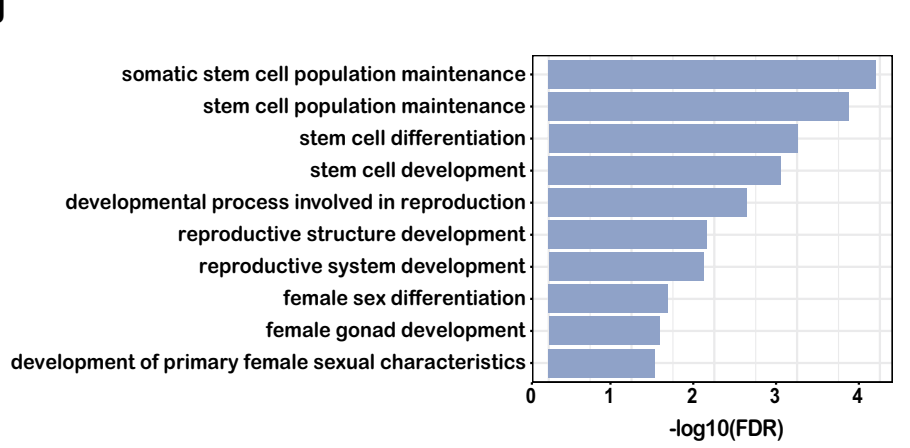

and aCALs, only in aCALs, and out of aCALs (M means median; $p$ value by Wilcoxon's test). $\mathbf{f}$ Expression of genes shared by CTCF and aCALs across five type of cells ( $M$ means median; $p$ value by Wilcoxon's test, ** represented $p<0.01, * * *$ represented $p<0.001)$. g GO enrichment of genes shared by aCALs and CTCF

\section{CTCF is required to maintain the high-order chromatin structure of FGSCs}

To explore whether CTCF affected the high-order chromatin structure of FGSCs, a Hi-C experiment was implemented for the CTCF knockdown group (Suppl. Table S4). We observed the change of TADs and A/B compartments between the CTCF knockdown group and control (Fig. 7a). Globally, we calculated the proportion of interactions of less than 20,40, 80,100 , or $120 \mathrm{~kb}$ versus total cis-interactions. The relative proportions of $\mathrm{cis}$-short interactions were decreased in the CTCF knockdown group, which recovered with the distance of interactions (Fig. 7b, Suppl. Figure S8A), suggesting that CTCF was implicated in short interactions such as chromatin loops and TADs. The numbers of TADs in the CTCF knockdown group were reduced compared with the control (Suppl. 
a

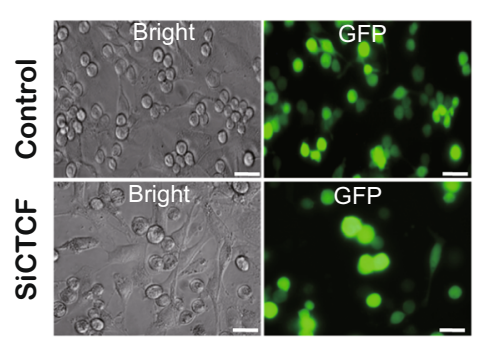

b

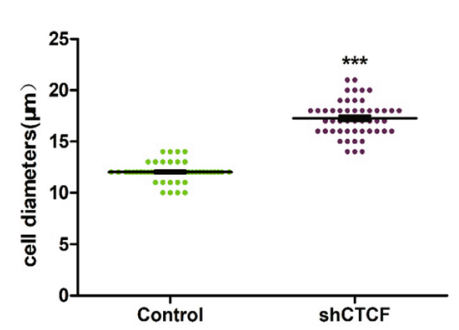

d

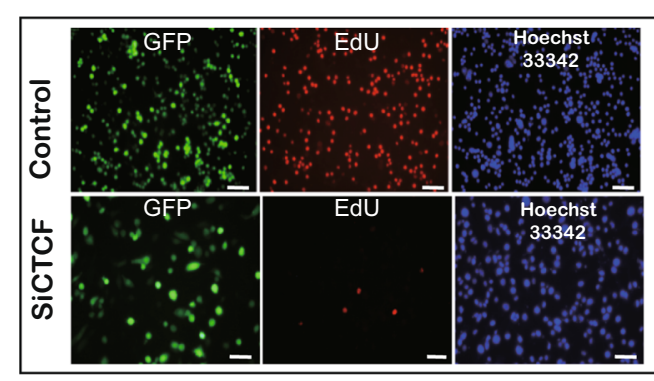

f

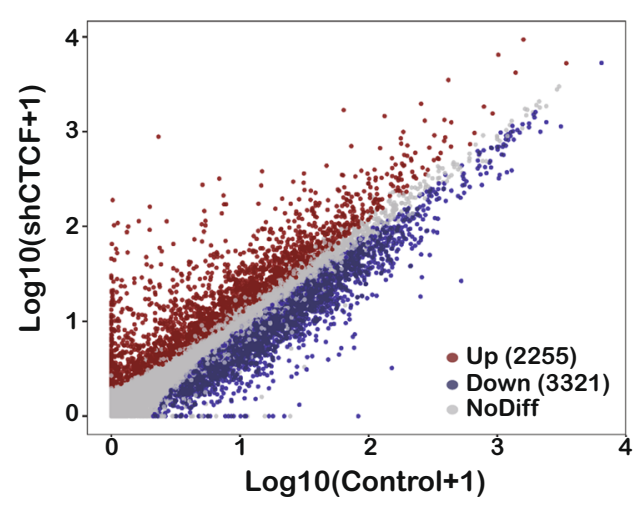

g

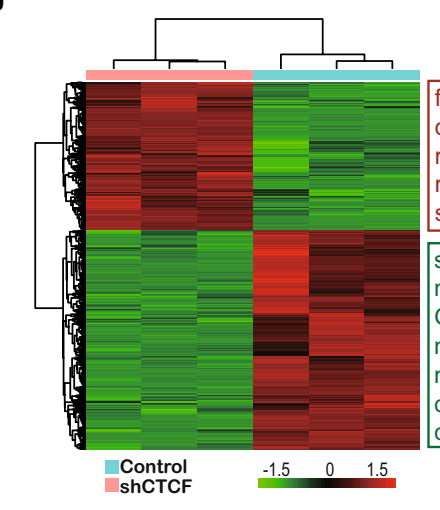

C

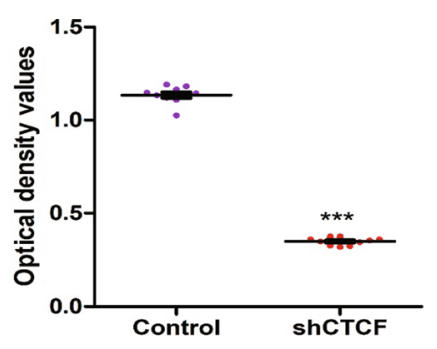

e

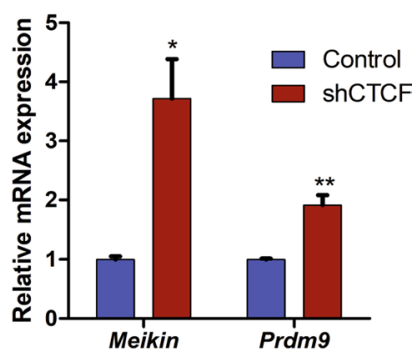

female gonad development

development of primary female sexual characteristics reproductive structure development reproductive system development stem cell differentiation

stem cell population maintenance mitiotic cell cycle

G1/S transition of mitotic cell cycle mitiotic sister chromatid segregation nuclear division chromatin organization chromatin remodeling
Fig. 6 Effect of CTCF knockdown on the biological functions of FGSCs. a Morphology of shCTCF-treated FGSCs and the control. Scale bar, $25 \mu \mathrm{m}$. b Cell sizes in shCTCF and control groups. c CCK8 assays of shCTCF-treated FGSCs and the control. d EdU incorporation assays of shCTCF-treated FGSCs and the control. Scale

Figure S8B). Furthermore, we found the high-order chromatin organization of CTCF knockdown group was closer to iPSCs and STOs (Fig. 7c), indicating that CTCF play an important role of maintaining the chromatin architecture of FGSCs.

To systematically evaluate the phenotype of CTCF in the high-order chromatin structure of FGSCs, we compared the Hi-C data between CTCF knockdown and control groups. TAD signals demonstrated that the CTCF knockdown group had significantly reduced strength of TADs compared with the control (Fig. 7d). A global change of the compartment status showed that the proportion of the A compartment was increased in the CTCF knockdown group (Fig. 7e). When compared with FGSC activation and repression compartments, we observed that some activation compartments had switched to repression in the CTCF knockdown group and vice versa (Suppl. Figure bar, $50 \mu \mathrm{m}$. e qRT-PCR analysis of Meikin and Prdm 9 expression in shCTCF-treated FGSCs and the control. f Scatter plot of genes with significant differential expression in shCTCF-treated FGSCs and the control. g Heat map and GO enrichment showed the gene expression and biological processes in shCTCF-treated FGSCs and the control

S8C). Genes located in the switching compartment tended to exhibit differential expression compared with the stable compartments (Suppl. Figure S8D). Importantly, CTCF knockdown dramatically reduced the number of chromatin loops, which had loss of about 95\% of chromatin loops (Suppl. Figure S8E). GO analysis of genes in the eliminated chromatin loops showed they were also involved in female development and stem cell population maintenance (Suppl. Figure S8F). Moreover, 1707 genes of aCALs did not form chromatin loops in the CTCF knockdown group, which included 1480 genes of CTCF-related aCALs (Suppl. Figure S9A). Combined with RNA-seq data, we finally identified 466 genes of CTCF-related aCALs, in which 212 genes were up-regulated and 254 genes were down-regulated in CTCF knockdown group (Suppl. Figure S9B, C). Among them, Notch2 showed higher expression than in the CTCF knockdown 


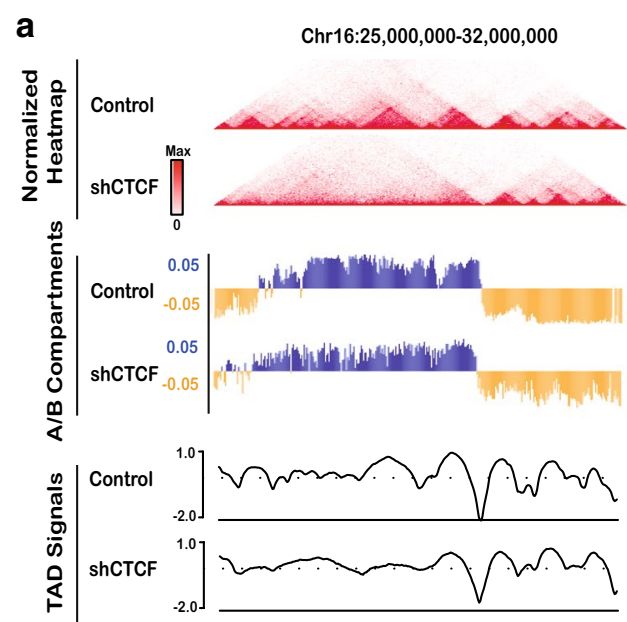

f

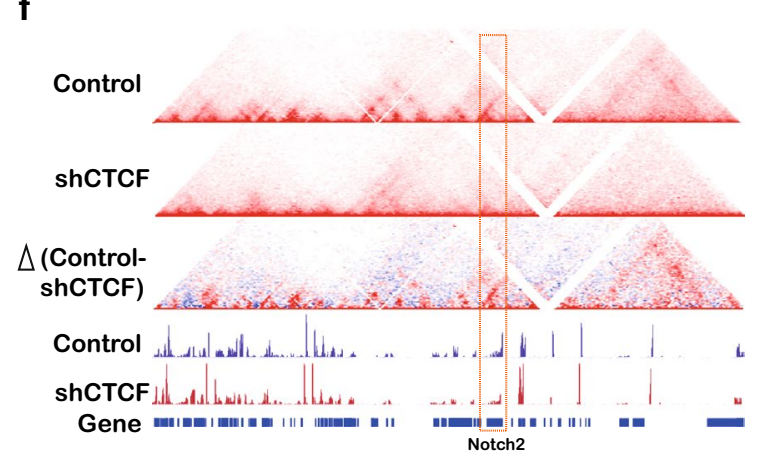

g
C

Relative Proportion of cis interactions

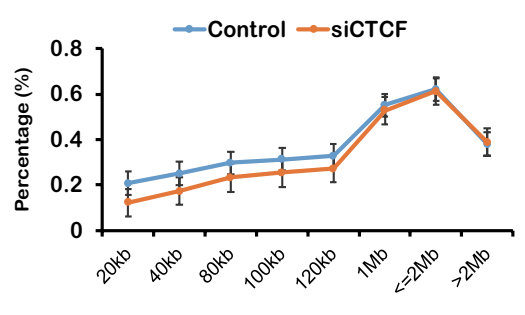

d

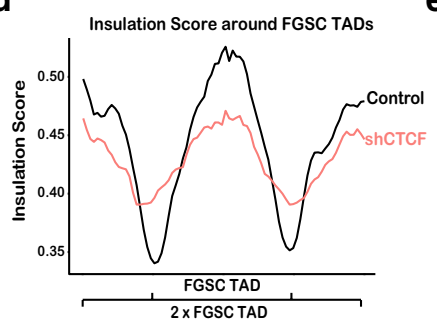

e
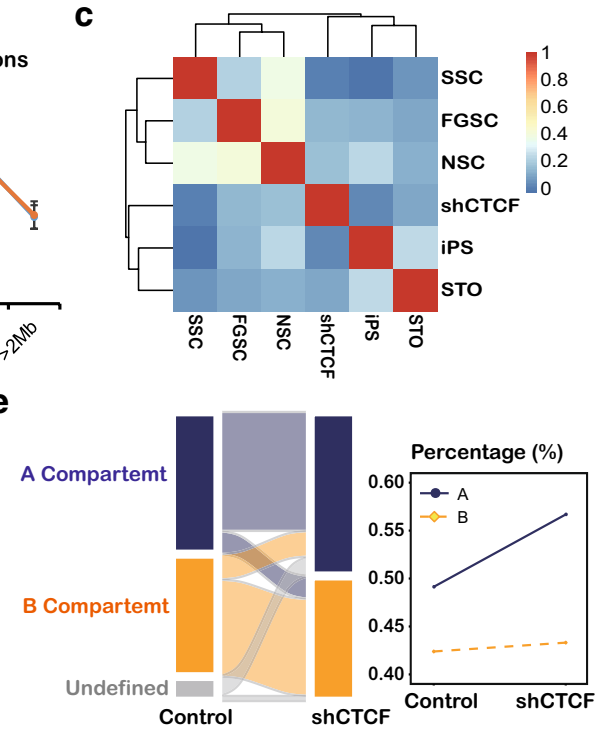

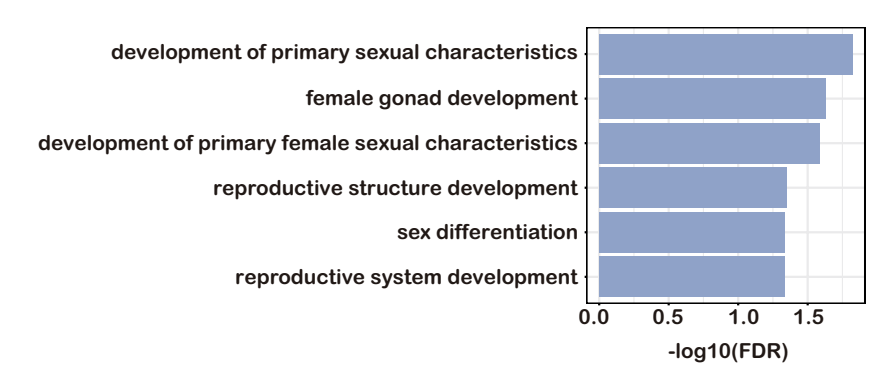

Fig. 7 CTCF is required to maintain the high-order chromatin structure of FGSCs. a Examples of contact matrices of chromosome 16 in shCTCF-treated FGSCs and the control. Normalized Hi-C interaction heat maps of $\mathrm{A} / \mathrm{B}$ compartments (A, blue; $\mathrm{B}$, orange) and TAD signals in shCTCF-treated FGSCs and the control at the $20 \mathrm{~kb}$ resolution. b Relative proportions of cis interactions at different genome distances versus total paired loci in shCTCF-treated FGSCs and the control. c Pearson correlation of PC1 value between shCTCF-treated

group in which it lost formation of the chromatin loop (Fig. 7f). These results indicated those genes were regulated by the formation of CTCF-mediated chromatin loops. Further analysis of enrichment of Gene Ontology showed that these genes were related to female development (Fig. $7 \mathrm{~g}$ ), which is consistent with previous findings. Taken together, these findings indicated that CTCF played an important role to maintain the high-order chromatin structure in FGSCs.

\section{Discussion}

Stem cells, which include pluripotent stem cells (ESCs and iPSCs) and ASCs, have important implications in basic biology and regenerative medicine. Our previous studies
FGSCs and other type of cells. d Average insulation scores (ISs) in shCTCF-treated FGSCs and the control at TADs and nearby regions. e Alluvial plots of the switch of the compartment status in shCTCFtreated FGSCs and the control. f Notch2 expression was reduced in shCTCF-treated FGSCs, which did not form chromatin loops. g GO enrichment of differentially expressed genes of CTC-related aCALs, which did not form chromatin loops in shCTCF-treated FGSCs

have shown that FGSCs exist in postnatal ovarian tissues of mice, rats, humans, and pigs [2, 4-6, 49]. As a novel ASC, FGSC had potential applications in biotechnology and medicine. Therefore, their isolation from adult ovaries, long-term culture, and regulation of self-renewal and differentiation have gained a great deal of interest in stem cell biology and reproductive medicine [2, 4-6, 50-52]. Zou et al. showed that long-term-cultured FGSCs from adult mammals differentiate into oocytes after transplantation in vivo and play an important role in maintaining female fertility [2]. White et al. isolated human FGSCs from adult ovaries and maintained long-term cultures of these cells [4]. Wu et al. characterized and traced the development of transplanted FGSCs of long-term culture in vivo [3]. By integrative epigenomic analysis, unique epigenetic 
signatures involved in unipotency of FGSCs have been revealed [32]. However, the regulatory mechanism of the FGSC signature based on the high-order chromatin structure remains to be explored.

To identify the chromosome structure characteristics of FGSCs, we compared FGSCs with pluripotent stem cells (iPSCs), ASCs (SSCs and NSCs), and somatic cells (STO cells) by Hi-C technology. The results revealed that FGSCs had a distinct high-order genome structure in terms of the A/B compartment status, chromatin loops, and TADs. For further characterization, we identified FGSC-specific activated and repressed compartment regions, and identified some genes that were highly related to the switch of the FGSC compartment status. These genes were related to stem cell maintenance and differentiation pathways, which strongly supports the role of FGSCs as ASCs with some shared characteristics with SSCs and NSCs. This suggests that the compartment status was highly specific to the cells. However, the further analysis of TADs showed that they were stable across stem cells, while chromatin loops analysis demonstrated that there were less shared chromatin loops, which indicated that chromatin loops may be another feature of the 3D chromatin structure. Hence, we propose that the regulation of the 3D chromatin architecture is not at a single level. By the combination of the distinct compartments and chromatin loops in FGSCs, we finally identified aCALs and repressed CALs in FGSCs. The results of GO analysis showed that the genes of aCALs were involved in female development and stem cell development, which suggested that these aCALs were features of FGSCs and consistent with FGSC biology. Our data indicated that the characteristics of FGSCs were regulated by cooperation through multiple levels of the high-order chromatin structure, such as the compartment status and chromatin loops, which has revealed the features of the 3D chromatin architecture.

By further exploring these specific chromatin loops, CTCF was identified as an important factor to regulate these features. Thus, we knocked down CTCF and found that CTCF knockdown inhibited FGSC proliferation and induced differentiation. Combined with RNA-seq and Hi-C results, we also found that the CTCF knockdown group lost most of the specific chromatin loops in which genes that did not form chromatin loops were enriched in female development. These findings not only revealed that CTCF is involved in maintaining the properties of FGSCs through regulating the high-order chromatin structure, but also suggested that FGSC development in vitro can be used to study female germline cell development.

Previous researches reported CTCF shaped the chromatin structure accompanied with cohesin complex [20, 53-55]. It raised a question whether cohesion complex is related with the maintenance of FGSCs. Several lines of evidence showed that cohesion complex was involved in the development of germline cells and stem cells. First, it is reported that cohesion complex played important role in meiosis process [56-58], which disruption of cohesion complex led to sterile in mouse. Secondly, cohesion complex is necessary for the maintenance of self-renewal genes in stem cells [59], which depletion of cohesin led to the abolishment of enhancer-promoter stabilization of self-renewal genes. Moreover, it is reported that cohesion complex not only maintain the self-renewal, but also can block the differentiation in epidermal progenitor cells and intestinal stem cells $[60,61]$. Last but most important, we found the expression of subunit of cohesin complex (SMC1a, SMC3, Rad21) was down-regulated in knock down CTCF FGSCs, suggesting that there was relationship between CTCF and cohesin complex. These findings suggested that cohesin complex is a potential factor to maintain the FGSCs in conjunction with CTCF.

\section{Conclusion}

In conclusion, we present a comprehensive overview of the chromatin organization in FGSCs to create a rich resource for genome-wide maps. Our findings revealed that the chromatin architecture of FGSCs included a unique compartment status and chromatin loops, especially aCALs, which may contribute to their cell type-specific gene regulation. Furthermore, CTCF was identified to play an important role in maintaining the biological functions of FGSCs by regulating the chromatin organization. These data provide a valuable resource for future studies of the features of chromatin organization in mammalian stem cells and further understanding of the fundamental features of FGSCs.

Supplementary Information The online version contains supplementary material available at https://doi.org/10.1007/s00018-021-04107-y.

Acknowledgements The authors thank Dr. Kang's lab (Tongji University) for providing the iPSCs cell line.

Author contributions GT, $\mathrm{XZ}$ and $\mathrm{CH}$ contributed equally to this work. GT performed the Hi-C experiments, analyzed the data and wrote the manuscript. XZ carried out ChIP-Seq experiments. $\mathrm{CH}$ did the $\mathrm{Hi}-\mathrm{C}$ experiment of knockdown of CTCF in FGSCs. WX and LW performed the NSC culture and identification. XL undertook the FGSC culture and identification. YW performed the SSC culture and identification. HL finished RNA-Seq experiment. JW, JL, and XZ supervised the experiment work and devised this study.

Funding This work was supported by National Key Research and Development Program of China (2017YFA0504201, 2018YFC1003501), National Nature Science Foundation of China (81720108017, 31871329), the National Major Scientific Instruments and Equipment Development Project, National Nature Science Foundation of China (61827814). 


\section{Declarations}

Conflict of interest The authors declared that there is no conflict of interest.

Ethical approval and consent to participate All procedures involving animals were approved by the Institutional Animal Care and Use Committee (IACUC) at Shanghai Jiao Tong University, and all experiments were performed in accordance with the approved protocols. The ethical approval number for our research is A2016084.

Consent for publication Not applicable.

Availability of data and material The accession number for the expression and sequencing data reported in this paper are in GEO: GSE126014, GEO: GSE137771 and GEO: GSE175730. All customer codes are publicly available via GitHub (https://github.com/skytguuu/ Geng_2019). All other data contained in the article and in its supplementary information are available upon request.

Open Access This article is licensed under a Creative Commons Attribution 4.0 International License, which permits use, sharing, adaptation, distribution and reproduction in any medium or format, as long as you give appropriate credit to the original author(s) and the source, provide a link to the Creative Commons licence, and indicate if changes were made. The images or other third party material in this article are included in the article's Creative Commons licence, unless indicated otherwise in a credit line to the material. If material is not included in the article's Creative Commons licence and your intended use is not permitted by statutory regulation or exceeds the permitted use, you will need to obtain permission directly from the copyright holder. To view a copy of this licence, visit http://creativecommons.org/licenses/by/4.0/.

\section{References}

1. Brinster RL, Zimmermann JW (1994) Spermatogenesis following male germ-cell transplantation. Proc Natl Acad Sci USA 91:11298-11302

2. Zou K, Yuan Z, Yang Z, Luo H, Sun K, Zhou L, Xiang J, Shi L, Yu Q, Zhang Y et al (2009) Production of offspring from a germline stem cell line derived from neonatal ovaries. Nat Cell Biol 11:631-636

3. Wu CQ, Xu B, Li XY, Ma WZ, Zhang P, Chen XJ, Wu J (2017) Tracing and characterizing the development of transplanted female germline stem cells in vivo. Mol Ther 25:1408-1419

4. White YA, Woods DC, Takai Y, Ishihara O, Seki H, Tilly JL (2012) Oocyte formation by mitotically active germ cells purified from ovaries of reproductive-age women. Nat Med 18:413-421

5. Ding X, Liu G, Xu B, Wu C, Hui N, Ni X, Wang J, Du M, Teng X, Wu J (2016) Human GV oocytes generated by mitotically active germ cells obtained from follicular aspirates. Sci Rep 6:28218

6. Zhou L, Wang L, Kang JX, Xie WH, Li XY, Wu CQ, Xu B, Wu J (2014) Production of fat-1 transgenic rats using a post-natal female germline stem cell line. Mol Hum Reprod 20:271-281

7. Lu YQ, He XC, Zheng P (2016) Decrease in expression of maternal effect gene Mater is associated with maternal ageing in mice. Mol Hum Reprod 22:252-260

8. Liu J, Shang DT, Xiao Y, Zhong P, Cheng HH, Zhou RJ (2017) Isolation and characterization of string-forming female germline stem cells from ovaries of neonatal mice. J Biol Chem 292:16003-16013
9. Zuckerman S (1951) The number of oocytes in the mature ovary. Recent Prog Horm Res 6:63-109

10. Borum K (1961) Oogenesis in the mouse: a study of the meiotic prophase. Exp Cell Res 24:495-507

11. Lieberman-Aiden E, van Berkum NL, Williams L, Imakaev M, Ragoczy T, Telling A, Amit I, Lajoie BR, Sabo PJ, Dorschner $\mathrm{MO}$ et al (2009) Comprehensive mapping of long-range interactions reveals folding principles of the human genome. Science 326:289-293

12. Smallwood A, Ren B (2013) Genome organization and long-range regulation of gene expression by enhancers. Curr Opin Cell Biol 25:387-394

13. Gorkin DU, Leung D, Ren B (2014) The 3D genome in transcriptional regulation and pluripotency. Cell Stem Cell 14:762-775

14. Dixon JR, Jung I, Selvaraj S, Shen Y, Antosiewicz-Bourget JE, Lee AY, Ye Z, Kim A, Rajagopal N, Xie W et al (2015) Chromatin architecture reorganization during stem cell differentiation. Nature 518:331-336

15. Wang Y, Wang HB, Zhang Y, Du ZH, Si W, Fan SX, Qin DD, Wang M, Duan YC, Li LF et al (2019) Reprogramming of meiotic chromatin architecture during spermatogenesis. Mol Cell 73:547-561.e546

16. Vara C, Paytuví-Gallart A, Cuartero Y, Le Dily F, Garcia F, SalvàCastro J, Gómez-H L, Julià E, Moutinho C, Cigliano RA (2019) Three-dimensional genomic structure and cohesin occupancy correlate with transcriptional activity during spermatogenesis. Cell Rep 28:352-367

17. Battulin N, Fishman VS, Mazur AM, Pomaznoy M, Khabarova AA, Afonnikov DA, Prokhortchouk EB, Serov OL (2015) Comparison of the three-dimensional organization of sperm and fibroblast genomes using the Hi-C approach. Genome Biol 16:77

18. Jung YH, Sauria MEG, Lyu X, Cheema MS, Ausio J, Taylor J, Corces VG (2017) Chromatin states in mouse sperm correlate with embryonic and adult regulatory landscapes. Cell Rep 18:1366-1382

19. Rao SSP, Huntley MH, Durand NC, Stamenova EK, Bochkov ID, Robinson JT, Sanborn AL, Machol I, Omer AD, Lander ES et al (2014) A 3D map of the human genome at kilobase resolution reveals principles of chromatin looping. Cell 159:1665-1680

20. Rao SSP, Huang SC, Glenn St Hilaire B, Engreitz JM, Perez EM, Kieffer-Kwon KR, Sanborn AL, Johnstone SE, Bascom GD, Bochkov ID et al (2017) Cohesin loss eliminates all loop domains. Cell 171:305-320.e324

21. Zuin J, Dixon JR, van der Reijden MIJA, Ye Z, Kolovos P, Brouwer RWW, van de Corput MPC, van de Werken HJG, Knoch TA, van Ijcken WFJ (2014) Cohesin and CTCF differentially affect chromatin architecture and gene expression in human cells. Proc Natl Acad Sci 111:996-1001

22. Nora EP, Goloborodko A, Valton AL, Gibcus JH, Uebersohn A, Abdennur N, Dekker J, Mirny LA, Bruneau BG (2017) Targeted degradation of CTCF decouples local insulation of chromosome domains from genomic compartmentalization. Cell 169:930-944. e922

23. Guo Y, Xu Q, Canzio D, Shou J, Li J, Gorkin DU, Jung I, Wu $\mathrm{H}$, Zhai Y, Tang Y et al (2015) CRISPR inversion of CTCF sites alters genome topology and enhancer/promoter function. Cell 162:900-910

24. Chen X, Ke Y, Wu K, Zhao H, Sun Y, Gao L, Liu Z, Zhang J, Tao W, Hou Z (2019) Key role for CTCF in establishing chromatin structure in human embryos. Nature 576:306-310

25. Okabe M, Ikawa M, Kominami K, Nakanishi T, Nishimune $Y$ (1997) 'Green mice' as a source of ubiquitous green cells. FEBS Lett 407:313-319

26. Zhang $\mathrm{C}, \mathrm{Wu} \mathrm{J}$ (2016) Production of offspring from a germline stem cell line derived from prepubertal ovaries of germline reporter mice. Mol Hum Reprod 22:457-464 
27. Gong X, Xie H, Li X, Wu J, Lin Y (2017) Bisphenol A induced apoptosis and transcriptome differences of spermatogonial stem cells in vitro. Acta Biochim Biophys Sin 49:780-791

28. Louis SA, Mak CK, Reynolds BA (2013) Methods to culture, differentiate, and characterize neural stem cells from the adult and embryonic mouse central nervous system. Methods Mol Biol 946:479-506

29. Guo W, Patzlaff NE, Jobe EM, Zhao X (2012) Isolation of multipotent neural stem or progenitor cells from both the dentate gyrus and subventricular zone of a single adult mouse. Nat Protoc 7:2005-2012

30. Xie W, Wang H, Wu J (2014) Similar morphological and molecular signatures shared by female and male germline stem cells. Sci Rep 4:5580

31. Wang G, Weng R, Lan Y, Guo X, Liu Q, Liu X, Lu C, Kang J (2017) Synergetic effects of DNA methylation and histone modification during mouse induced pluripotent stem cell generation. Sci Rep 7:1-12

32. Zhang XL, Wu J, Wang J, Shen T, Li H, Lu J, Gu Y, Kang Y, Wong CH, Ngan CY et al (2016) Integrative epigenomic analysis reveals unique epigenetic signatures involved in unipotency of mouse female germline stem cells. Genome Biol 17:162

33. Servant N, Varoquaux N, Lajoie BR, Viara E, Chen CJ, Vert JP, Heard E, Dekker J, Barillot E (2015) HiC-Pro: an optimized and flexible pipeline for $\mathrm{Hi}-\mathrm{C}$ data processing. Genome Biol 16:259

34. Langmead B, Salzberg SL (2012) Fast gapped-read alignment with Bowtie 2. Nat Methods 9:357-359

35. Imakaev M, Fudenberg G, McCord RP, Naumova N, Goloborodko A, Lajoie BR, Dekker J, Mirny LA (2012) Iterative correction of Hi-C data reveals hallmarks of chromosome organization. Nat Methods 9:999-1003

36. Naumova N, Imakaev M, Fudenberg G, Zhan Y, Lajoie BR, Mirny LA, Dekker J (2013) Organization of the mitotic chromosome. Science 342:948-953

37. Servant N, Lajoie BR, Nora EP, Giorgetti L, Chen CJ, Heard E, Dekker J, Barillot E (2012) HiTC: exploration of high-throughput "C" experiments. Bioinformatics 28:2843-2844

38. Dixon JR, Selvaraj S, Yue F, Kim A, Li Y, Shen Y, Hu M, Liu JS, Ren B (2012) Topological domains in mammalian genomes identified by analysis of chromatin interactions. Nature 485:376-380

39. Crane E, Bian Q, McCord RP, Lajoie BR, Wheeler BS, Ralston EJ, Uzawa S, Dekker J, Meyer BJ (2015) Condensin-driven remodelling of $\mathrm{X}$ chromosome topology during dosage compensation. Nature 523:240-244

40. Li H, Handsaker B, Wysoker A, Fennell T, Ruan J, Homer N, Marth G, Abecasis G, Durbin R, Genome Project Data Processing Subgroup (2009) The sequence alignment/map format and SAMtools. Bioinformatics 25:2078-2079

41. Ramirez F, Dundar F, Diehl S, Gruning BA, Manke T (2014) deepTools: a flexible platform for exploring deep-sequencing data. Nucleic Acids Res 42:W187-191

42. Pertea M, Kim D, Pertea GM, Leek JT, Salzberg SL (2016) Transcript-level expression analysis of RNA-seq experiments with HISAT, StringTie and Ballgown. Nat Protoc 11:1650-1667

43. Trapnell C, Roberts A, Goff L, Pertea G, Kim D, Kelley DR, Pimentel H, Salzberg SL, Rinn JL, Pachter L (2012) Differential gene and transcript expression analysis of RNA-seq experiments with TopHat and Cufflinks. Nat Protoc 7:562-578

44. Huang DW, Sherman BT, Lempicki RA (2009) Systematic and integrative analysis of large gene lists using DAVID bioinformatics resources. Nat Protoc 4:44-57

45. Su G, Morris JH, Demchak B, Bader GD (2014) Biological network exploration with Cytoscape 3. Curr Protoc Bioinform 47:8.13.11-8.13.24
46. Nagao M, Ogata T, Sawada Y, Gotoh Y (2016) Zbtb20 promotes astrocytogenesis during neocortical development. Nat Commun $7: 1-14$

47. Du Z, Zheng H, Huang B, Ma R, Wu J, Zhang X, He J, Xiang Y, Wang Q, Li Y et al (2017) Allelic reprogramming of 3D chromatin architecture during early mammalian development. Nature 547:232-235

48. Aldiri I, Xu B, Wang L, Chen X, Hiler D, Griffiths L, Valentine M, Shirinifard A, Thiagarajan S, Sablauer A et al (2017) The dynamic epigenetic landscape of the retina during development, reprogramming, and tumorigenesis. Neuron 94:550-568.e510

49. Hou L, Wang J, Li X, Wang H, Liu G, Xu B, Mei X, Hua X, Wu J (2018) Characteristics of female germline stem cells from porcine ovaries at sexual maturity. Cell Transplant 27:1195-1202

50. Zou K, Hou L, Sun K, Xie W, Wu J (2011) Improved efficiency of female germline stem cell purification using fragilis-based magnetic bead sorting. Stem Cells Dev 20:2197-2204

51. Zhang Y, Yang Z, Yang Y, Wang S, Shi L, Xie W, Sun K, Zou K, Wang L, Xiong J et al (2011) Production of transgenic mice by random recombination of targeted genes in female germline stem cells. J Mol Cell Biol 3:132-141

52. Bai Y, Yu M, Hu Y, Qiu P, Liu W, Zheng W, Peng S, Hua J (2013) Location and characterization of female germline stem cells (FGSC s) in juvenile porcine ovary. Cell Prolif 46:516-528

53. Haarhuis JHI, van der Weide RH, Blomen VA, Yáñez-Cuna JO, Amendola M, van Ruiten MS, Krijger PHL, Teunissen H, Medema RH, van Steensel B et al (2017) The cohesin release factor WAPL restricts chromatin loop extension. Cell 169:693-707. e614

54. Hansen AS, Pustova I, Cattoglio C, Tjian R, Darzacq X (2017) $\mathrm{CTCF}$ and cohesin regulate chromatin loop stability with distinct dynamics. Elife 6:e25776

55. Zuin J, Dixon JR, van der Reijden MI, Ye Z, Kolovos P, Brouwer RW, van de Corput MP, van de Werken HJ, Knoch TA, van IJcken WV et al (2014) Cohesin and CTCF differentially affect chromatin architecture and gene expression in human cells. Proc Natl Acad Sci USA 111:996-1001

56. Revenkova E, Eijpe M, Heyting C, Hodges CA, Hunt PA, Liebe $\mathrm{B}$, Scherthan H, Jessberger R (2004) Cohesin SMC1 $\beta$ is required for meiotic chromosome dynamics, sister chromatid cohesion and DNA recombination. Nat Cell Biol 6:555-562

57. Ishiguro K, Kim J, Shibuya H, Hernández-Hernández A, Suzuki A, Fukagawa T, Shioi G, Kiyonari H, Li XC, Schimenti J et al (2014) Meiosis-specific cohesin mediates homolog recognition in mouse spermatocytes. Genes Dev 28:594-607

58. Brieño-Enríquez MA, Moak SL, Toledo M, Filter JJ, Gray S, Barbero JL, Cohen PE, Holloway JK (2016) Cohesin removal along the chromosome arms during the first meiotic division depends on a NEK1-PP1 $\gamma$-WAPL axis in the mouse. Cell Rep 17:977-986

59. Kagey MH, Newman JJ, Bilodeau S, Zhan Y, Orlando DA, van Berkum NL, Ebmeier CC, Goossens J, Rahl PB, Levine SS et al (2010) Mediator and cohesin connect gene expression and chromatin architecture. Nature 467:430-435

60. Noutsou M, Li J, Ling J, Jones J, Wang Y, Chen Y, Sen GL (2017) The cohesin complex is necessary for epidermal progenitor cell function through maintenance of self-renewal genes. Cell Rep 20:3005-3013

61. Khaminets A, Ronnen-Oron T, Baldauf M, Meier E, Jasper H (2020) Cohesin controls intestinal stem cell identity by maintaining association of Escargot with target promoters. Elife 9:e48160

Publisher's Note Springer Nature remains neutral with regard to jurisdictional claims in published maps and institutional affiliations. 